\title{
THE EFFECTS OF COMPUTER ANIMATION AND COGNITIVE STYLE ON THE UNDERSTANDING AND RETENTION OF SCIENTIFIC EXPLANATION
}

\author{
by \\ Sookyoung Lee \\ Dissertation submitted to the Faculty of the \\ Virginia Polytechnic Institute and State University \\ in partial fulfillment of the requirements for the degree of
}

\section{DOCTOR OF PHILOSOPHY}

in

Teaching and Learning

APPROVED:


Key Words: Animation, Cognitive-Style, Multimedia-Instruction, Science-Instruction 


\title{
THE EFFECTS OF COMPUTER ANIMATION AND COGNITIVE STYLE ON THE UNDERSTANDING AND RETENTION OF SCIENTIFIC EXPLANATION
}

\author{
by \\ Sookyoung Lee \\ Committee Chairman: J. K. Burton \\ Teaching and Learning
}

(ABSTRACT)

Advances in computer technology have made it possible for educators to develop their own multimedia instructional materials using visuals such as animation. Despite the increased use of animation in the multimedia instructional materials, there is still relatively little research regarding the way in which students benefit from the attributes of computer animation. As a result, additional studies on the instructional attributes of animation are required to confirm the animation effect in the learning process.

The purpose of this study was to investigate the effect of animation in the enhancement of the problem-solving and retention of scientific concepts in computer based modules across learners possessing different cognitive styles. In this study, 121 undergraduate and graduate students were classified as field-independent, field-neutral, or field-dependent as a result of their performance on the Group Embedded Figures Test. Participants were randomly assigned to either animation and narration treatment group $(\mathrm{N}=61)$ or static visual and narration treatment group $(\mathrm{N}=60)$. Problem-solving 
and recall tests were conducted immediately after the completion of each treatment. Participants receiving an animation treatment performed significantly better than those receiving a static visual treatment on problem-solving but not on recall. Fielddependent students in the animation group generated approximately $40 \%$ more correct solutions to the problem-solving test than those in the static visual group. The results of this study indicate that animation may be an effective tool in promoting problemsolving of scientific concepts, especially for field-dependent learners who have difficulty acquiring and processing visual information. 


\section{DEDICATION}

To my parents, who are always in all of my heart and who have made sacrifices during all my moments that led to this time of accomplishment...

to my parents-in-law, who are always full of love, support, and encouragement...

and to my husband, who traveled together with me through the high and low moments during this journey with his understanding, patience,

...and whole-hearted love that helped lighten my burden. WE DID IT! 


\section{ACKNOWLEDGEMENTS}

I would like to express my sincere appreciation to the following members of my doctoral committee: Dr. Melanie Biermann, Dr. Norman Dodl, Dr. Glen Holmes, and Dr. Mike Moore. I am grateful to each for their continuous guidance, encouragement, and support throughout every phase of the study.

Special thanks go to my advisor, Dr. John Burton, respected educator, who offered invaluable advice, encouragement, and assistance. He has shown his caring and given his support - moral and professional - above and beyond the call of duty. Without his constant and whole-hearted guidance, this study would not exist.

I am greatly indebted to my colleagues and friends, Mary Pennington, Ernie Joy, Carmel Vaccare, and Julia Harbeck for their encouragement, understanding, and enjoyment throughout the graduate study. Your support and friendship will always be remembered.

Finally, I want to extent my special thanks and warm regards to Dr. and Mrs. $\mathrm{Mu}-\mathrm{Keun}$ Lee whose presence and support have made significant contributions to my personal and professional development. 


\section{TABLE OF CONTENTS}

ABSTRACT

\section{CHAPTER}

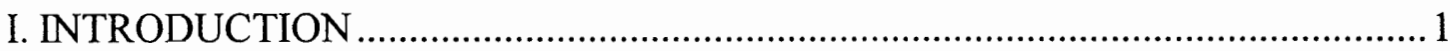



Animation ................................................................................. 4

The Definition of Animation .................................................... 4

Theoretical Support ............................................................. 6

Mental Imagery ......................................................... 6

Dual-Coding Theory and Levels-of-Processing View...............9

Conceptual Model ........................................................ 12

Empirical Support ................................................................... 13

Fidelity of Animation ...................................................... 14

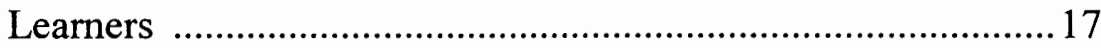

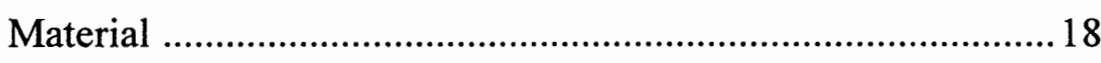

$\sqrt{ }$ Assessment Technique ....................................................19

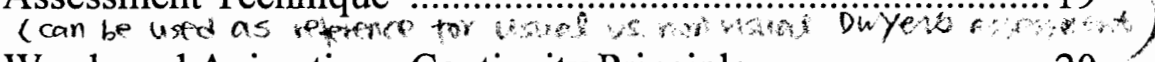

Words and Animation : Contiguity Principle .........................20

Animation and Science Instruction ........................................... 21

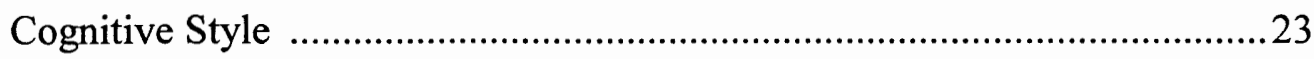


The Definition of Cognitive Style ………………….........................23

Visual-Spatial Ability and Experiments .............................................24

Spatial Perception ................................................................... 24

Spatial Visualization.................................................................... 26

Field-Dependence/Independence Effects on Learning .......................27

Research on Effective Strategies for Field-Dependents .....................29

Manipulating Instructional Materials ........................................29

Training Restructioning ability .................................................... 32

Gender Differences and Degree of Field-Dependence ........................34

Field-Dependent Learners and Science Instruction ............................35

Animation: An Effective Cueing strategy for Field-Dependents in

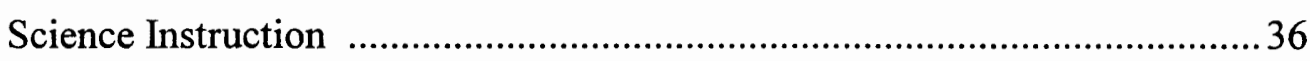

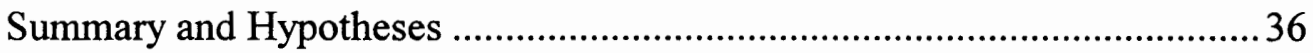

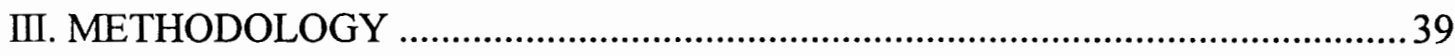

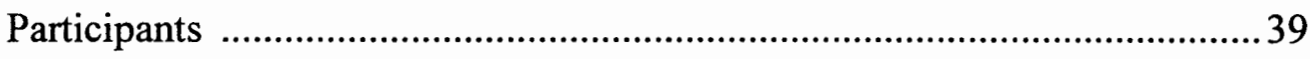

Research Design .........................................................................................40

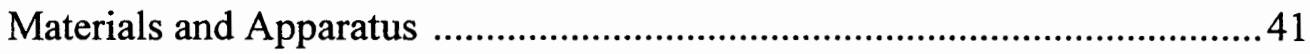

Computer-Based Materials ................................................................ 41

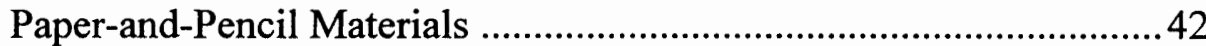

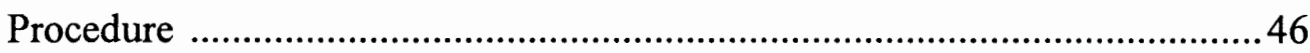

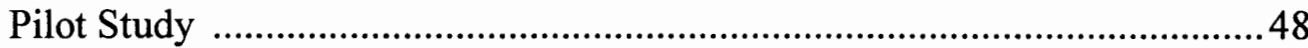

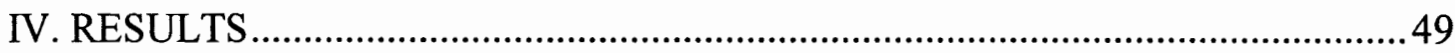

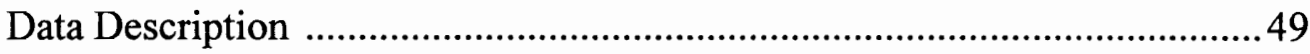

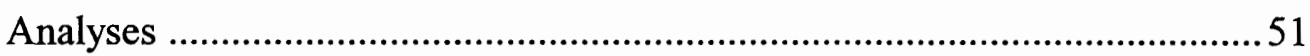

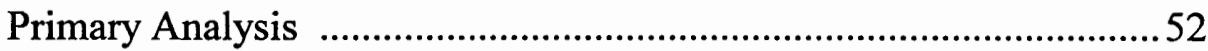

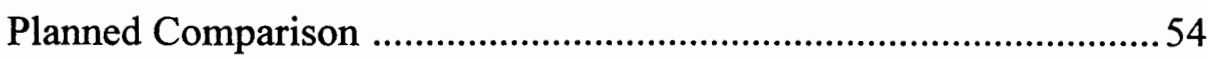


V. SUMMARY, DISCUSSION, AND CONCLUSION .57

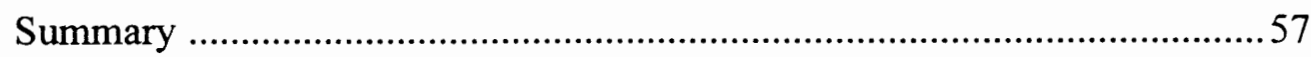

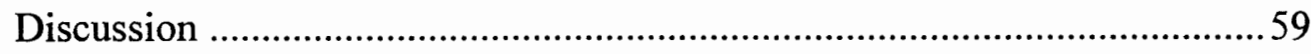

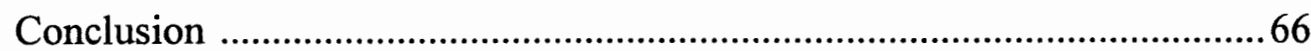

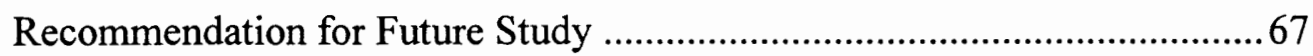

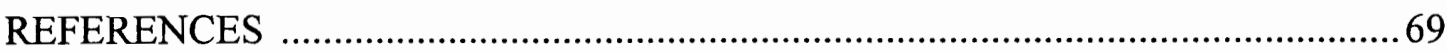

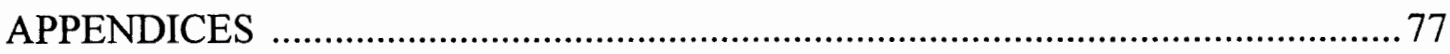

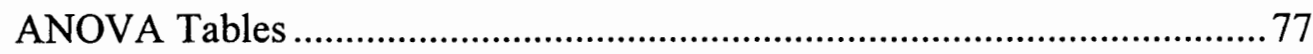

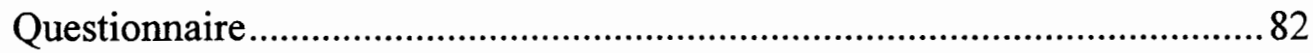

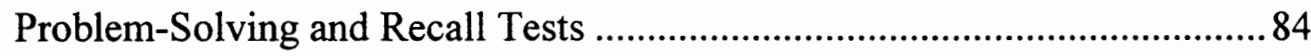

Example of the Computer Program Screen ................................................ 87

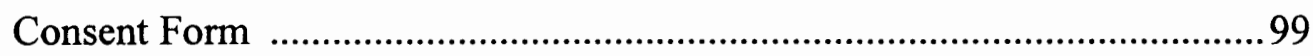

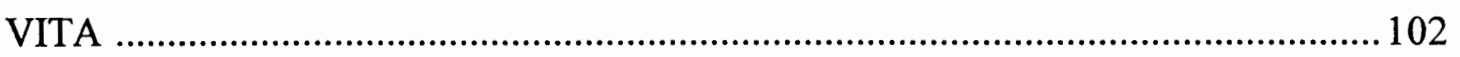




\section{LIST OF TABLES}

Table

$\underline{\text { Page }}$

1. Means and Standard Deviations of Students' Scores on the Problem-Solving and Recall Tests per Treatment

2. Means and Standard Deviations by Group on the Problem-Solving and Recall Tests.

3. Means of Field-Independent, Field-Neutral, and Field-Dependent Participants on the Problem-Solving and Recall Tests.....

4. Means and Standard Deviations of Field-Dependent Participants' Scores per Each Treatment on the Problem-Solving and Recall Tests 56 


\section{LIST OF FIGURES}

Figure

$\underline{\text { Page }}$

1. A Dual-Coding Model for Memory and Cognition .................................... 10

2. Hypothesized Relationship of Fidelity and Learning ............................. 16

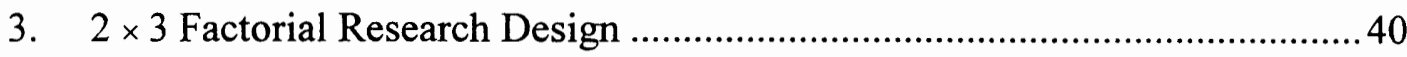

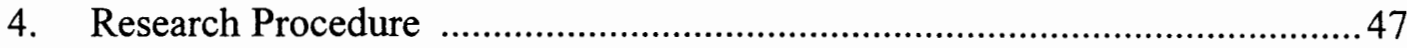

5. Mean Problem-Solving Scores for Field-Independents and FieldDependents in Each Animated and Static Visual Group .63 


\section{CHAPTER I}

\section{INTRODUCTION}

Advances in computer technology have made it possible for educators to create multimedia instructional environments which are designed to provide students with a broad diversity of learning experiences through the use of text, graphics, animation, sound, and video. Animation, especially as used in multimedia, has attracted the attention of instructional program developers as new software and hardware have made it increasingly easy to produce (Mayer \& Anderson, 1991). As a result, more and more developers of educational programs have begun to incorporate animation into their instructional products.

The most noteworthy features that animation bring to the instructional environment are motion and trajectory (Rieber, 1990). These two perceptual characteristics allow animated visuals to offer the potential for increased learning of concepts and principles involving changes over time or in a certain direction. Animation makes these cognitive learning tasks concrete and vivid by showing motion and direction directly to the learner. This can reduce the level of abstraction for such learning tasks and increase the potential for successful understanding of the visualspatial information presented. Therefore, animated visual materials are more likely to provide clear benefits for learners who especially have difficulty perceiving visualspatial information. 
The visual-spatial perception of learners has been widely researched in terms of the larger construct of cognitive style. Specifically, the way an individual perceives and acquires information from visual materials is described as bipolar cognitive style: field-dependence and field-independence (Witkin \& Goodenough, 1981). Those individuals who can easily analyze and process visual-spatial information are called field-independent, while those who have difficulty recognizing and acquiring visualspatial information, field-dependent. Usually, findings indicate that field-dependent learners perform lower on visual-spatial tasks than field-independent learners, because field-dependents fail to focus attention on the critical and essential elements of a visual field (Witkin, 1950; Witkin, Moore, Goodenough, \& Cox, 1977). Because the dynamic features of animation are likely to cue students' attention to meaningful elements of visuals and effectively emphasize the important cues of information, animation can be an effective tool or aid to improve field-dependent learners' performance on visual learning tasks. The adequate use of the unique attributes of animation can compensate field-dependents' lower performance rates of perception on visual-spatial information.

In order to create efficient animated materials which improve the acquisition of visual-spatial information by field-dependent learners, instructional developers must consider the unique attributes of animation which are particularly suitable for the demands of the instructional content, such as science. In general, science deals with a series of changes among parts of systems, objects, or events. Animation effectively 
depicts these actions as well as the causal relations among them. This makes animation a desirable and useful instructional device for teaching scientifíc explanations and concepts. The variety of colors and motions in animated presentations can also add realism and stimulate students' interest in the subject of science. Thus, animation in science instruction may have a strong potential for overcoming the decline in attitudes toward science that has been especially prevalent among females.

The purpose of this study is to explore the attributes of animation and their relationships to the cognitive style known as field-dependence and field-independence with the goal of enhancing the understanding and retention of scientific concepts in computer-based modules across learners possessing different cognitive style. Because there is no research available which investigates the interaction between animation and cognitive style in science instruction, this study will make a unique contribution to the theoretical and empirical rationale underlying the implementation of animation in the teaching and learning process. It is hoped that this study will shed light on how instructional designers can better develop computer animations which improve and facilitate student learning, particularly in science. 


\section{CHAPTER II}

\section{REVIEW OF THE LITERATURE}

\section{Animation}

\section{The Definition of Animation}

Animation is defined as "the process of generating a series of frames containing an object or objects so that each frame appears as an alteration of the previous frame in order to show motion" (Baek \& Layne, 1988, p. 132). Large, Beheshti, Breuleus, and Renaud (1995) also define animation as "a series of rapidly changing ... screens that present the illusion of movement" (p. 4). In short, animation is interpreted as a visual which demonstrates the consequence of its movement.

The display format of moving images has progressed from film to computer animation. Film animation is made up on the basis of the chemical process of photography; whereas computer animation is created through the digitizing process of visuals (Heinich, Molenda, \& Russell, 1993). Basically, film animation consists of a series of photographed still images. When these images are sequentially projected on a screen, they are perceived as a continuous moving image, because of the illusion of motion caused by the persistence of human vision (May \& Lumsdaine, 1958). Owing to the continuous improvement of computer software and hardware which allow 
creation and manipulation of visual images, animation has recently been created without using photographed pictures.

Animation whether on computer, film, or otherwise, is not real motion, but only the illusion of motion. (Rieber \& Kini, 1991). Although both film and computer depict movement, the computer format allows more flexibility and capability than film format in the instructional environment. Using index and hypertext, instructors and learners can locate specific sections of a program in computer animation. Computer animation can also provide forward and backward search capabilities. As a result, the computer generated animation is used more and more in instructional programs to depict the movement of objects.

Animation provides the unique attributes of motion and trajectory, usually not found in static visuals (Rieber, 1990). First, presentation of motion by the illusion of movement is the most obvious characteristic of animated visuals. Animated visuals are probably better at presenting ideas involving changes of an object over time than static visuals because of their ability to show motion. As with motion, trajectory is another unique and distinguishing attribute of animation. Trajectory refers to the path traveled by the moving object (Klein, 1987). This characteristic allows animated visuals to easily describe the changes in the direction of a moving object. These two perceptual characteristics of animation (i.e., motion and trajectory) are unique attributes which distinguish animated visuals from static visuals. 
In short, the creation of dynamics through motion and trajectory is the most noteworthy contribution of animation to the instructional environment. In order to design effective animated visuals for instructional purposes, instructional designers should consider that animation provides the following functions: (1) "adequate and accurate visualization of differences in the motion of objects (i.e., moving, not moving)" ; and (2) "adequate and accurate visualization of the trajectory of objects (i.e., direction of the path of the moving object)" (Rieber, Boyce, \& Assad, 1990, p. $50)$.

\section{Theoretical Support: "Why Animation Instead of Static Visuals?"}

When designing animated instructional materials, one question should be asked: "Why do we need to use animation instead of static pictures ?" The following section is an attempt to answer this question by examining and describing the relevant theories on the use of animation in instruction.

\section{Mental Imagery}

The superiority of animation for learning tasks has been ascribed to its facilitating effect on the development of mental imagery (Purnell \& Solman, 1991). Mental imagery of learners can be built by internal and/or external imaging devices (Rieber, Boyce, \& Assad, 1990). The verbal presentation of material, such as text and narration, can be categorized as an internal imaging device when it is designed to 
support the learners' capability to image information. That is, text and narration are often intended to sufficiently provide all information by way of highly imaginable explanations and examples. On the other hand, pictorial graphics are considered to be external imaging devices which provide visualized concrete information directly to the learner. This type of imaging device helps learners build runnable mental images easily, providing enhanced comprehension and recall of information presented (Purnell \& Solman, 1991).

Before any graphic materials are provided in instructional environments, a need for external aids to visualization must be verified (Rieber, 1994). If a textual passage prompts adequate internal imaging by learners, then the inclusion of external visual aids such as graphics will not be necessary for successful and accurate learning. There exists the potential that unnecessary graphics may result in the distraction of students' learning in some way. Thus, it is important that instructional designers establish the need for external imaging aids before adding visuals for increased learning.

Animation and static visuals are subsets of external imaging devices in the development of mental images. Although both animated and static graphics serve similar roles as external imaging devices, animation has been shown to be superior to static graphics in facilitating mental imagery. Research conducted by Baek and Layne (1988) indicates that students provided with animation presentation perform better than students with static visuals. Also, Williamson and Abraham's (1995) research has shown that animated instruction produces higher conceptual understanding scores 
than static visuals. They conclude that the treatment of animation may increase conceptual understanding by prompting the formation of dynamic mental images of the phenomena.

The reason for the superior effect of animation relative to static graphics is that animation is especially efficient for depicting motion and trajectory of objects as well as spatial information (Rieber, 1990). Static visuals would probably be sufficient for learning tasks that only demand learners' visualization of still information. However, when a learning task requires learners to understand ideas involving changes over time or in a certain direction, static graphics can only enable learners to mentally construct these dynamic parts of images on their own. That is, static visuals fail to depict the dynamic nature of many of the processes of such an instructional task. Static visuals may form static mental images that fail to provide adequate understanding of the dynamic nature of the phenomena, and instead, cause misconception about the phenomena (Williamson \& Abraham, 1995). However, animated visuals are likely to increase learners' potential for accurate and successful mental imagery on this type of cognitive task because of their ability to show motion and trajectory. By providing motion and trajectory attributes directly to learners, animation can help reduce the level of abstraction of such learning tasks and induce more vivid and apparent mental imaging by learners.

In short, animation is an efficient visual aid in facilitating the development of mental imagery of dynamic information involving changes of an object over time or 
changes in the direction of the moving object, because of its ability to depict motion and trajectory. The dynamic qualities of animation allow a more detailed view of instructional material presented and, thus, mental images aroused by animation are likely to be more precise, adequate, and vivid than those represented by static visuals.

\section{Dual-Coding Theory and Levels-of-Processing View}

Dual-coding theory, developed by Paivio (1986), provides theoretical support for the use of animated visuals in the teaching and learning process. According to this theory, it is assumed that memory consists of two separate systems or codes - visual and verbal. Figure 1 represents Paivio's dual coding model for describing the relation between verbal and visual systems. The visual system is thought of as a code for visual information, while the verbal system is specialized for verbal information. Two types of information (words and pictures) activate one or both of these visual and verbal codes. These codes are functionally and structurally independent, and one can be activated without the other, or they can work in tandem. Although these two coding systems are assumed to be independent of one another, they can be interconnected so that information in one system can be encoded by the other system. That is, information processing in memory involves interactions between these two coding systems. Paivio (1986) contends that the availability of this dual access differs, and verbal codes for pictures are more available than visual codes for words, so visual pictures are much more likely to be dually encoded than verbal material. 


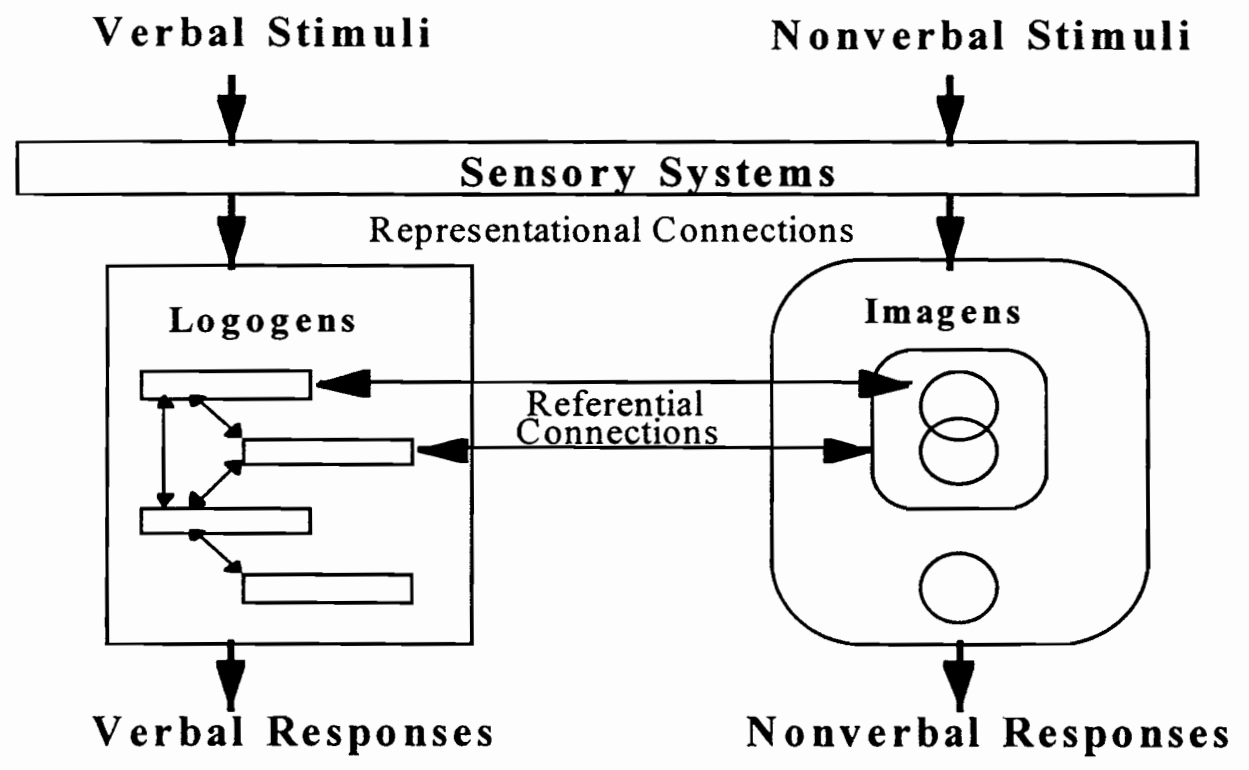

Figure 1. A Dual-Coding Model for Memory and Cognition (Paivio, 1986)

When information is highly imaginable and concrete, a learner can encode the information into long-term memory using both verbal and visual codes (Paivio, 1986). Because the dynamic qualities of animation depict more accurate, complete, and detailed information than static pictures, it is likely that animated visuals more effectively facilitate dual access to long-term memory than still pictures. This redundant dual encoding is likely to increase the probability of retrieval so that learning using animated visuals can promote recall and comprehension of learners (Kobayashi, 1986; Paivio, 1986; Rieber, 1994; Rieber, Boyce, \& Assad, 1990). 
According to Craik and Lockhart (1972), encoding information in both types of codes is likely to lead to a greater depth and breadth of processing of content in memory (Purnell \& Solman, 1991). Memory is influenced not only by depth of processing but also breadth of processing. Depth of processing is defined as "the amount of meaningfulness extracted from the stimulus material," and breadth of processing as "the breadth of analysis within any given level or domain encoding" (Kobayashi, 1986). Craik and Lockhart (1972) suggest that content accessed in two forms of codes (verbal and visual) result in greater depth of processing, because "it requires greater effort to integrate the two in memory" (Purnell \& Solman, 1991, p. 281). Also, greater breadth of processing would occur when the same content is encoded in two different forms, because the information can be elaborated in many different ways (Purnell \& Solman, 1991). Animated and static visual material provide both verbal and nonverbal information, allowing for a greater depth and breadth of processing in memory. In comparison, animation is likely to promote much deeper and broader encoding of information than static pictures because of the dynamic quality of animation (Alessi, 1988; Rieber, 1990a). Animation, as a dynamic picture, triggers deeper and broader coding which, in turn, allows learners to have a stronger memory trace and to remember information longer. 


\section{Conceptual Model}

Mayer (1989) invested considerable effort to develop instructional techniques for improving students' understanding of scientific explanations. Building a conceptual model is one promising technique of which he has stressed the importance. According to Mayer (1989), a conceptual model is "words and/or diagrams that are intended to help learners build mental models of the system being studied; a conceptual model highlights the major objects and actions in a system as well as the causal relations among them" (p. 43).

For the successful application of conceptual models to instructional design, the following aspects should be considered: the target system, the learner's mental model of the target system being studied, and the construction of a conceptual model of the target system (Rieber, 1994). The target system is defined as the actual object, system, concept, or phenomena that an individual is trying to learn. Examples of target systems are kinematics, hydraulics, or even a bicycle. The learner's mental model refers to a learner's personal understanding as to the target system being studied. In fact, a case could be made that the learner's mental model might not be "an accurate reflection of the target system" (Rieber, 1994, p. 223). In order to aid the learner in building a more precise mental model for a target system presented, a conceptual model is developed and provided for the individual learner by instructional designers. This conceptual model plays an important role as a link between the target system and a learner's 
mental model, facilitating an individual learner to accurately understand the target system that one is trying to study.

The understanding of a target system, especially related to scientific concepts, involves building a dynamic mental model of the target system. Such a mental model of the target system can be effectively generated by such conceptual models as illustrations, graphics, and animations. These conceptual models are likely to not only foster students' understanding of scientific information but also to improve students' ability to transfer problem-solving techniques. Because they can mentally run and manipulate their mental model corresponding to each situation, a student who has built a mental model from graphic or animation can more easily transfer what they learned to new problem situations, Animation can be a good conceptual model for the learner's understanding of a scientific system, because the dynamic qualities of animation allow depicting motion and trajectory of objects as well as spatial information. In fact, animated visuals help individual learners develop and modify their own mental models into more accurate ones with regard to target systems being studied. Thus, the mental models generated by animation tend to be more precise and vivid than those aroused by other conceptual models.

\section{Empirical Support: Conditions Needed for Effective Use of Animation}

Existing educational research literature has shown inconsistent results of the effectiveness of animation in the learning process (Baek and Layne, 1988; Mayer \& 
Anderson, 1991; Rieber, 1990). Research studies conducted by Reed (985), and Doll (1986) have failed to show that animation facilitate learning. The possible reason for the negative results is that many studies on animation do not use appropriate research conditions for meaningful learning (Mayer \& Anderson, 1991; Mayer \& Anderson, 1992; Mayer \& Sims, 1994). Mayer proposes the general criteria for successful instructional conditions for effective use of animation in improving student learning. The criteria involve the type of fidelity, the type of learner, the type of instructional material, and the type of assessment technique (Alessi, 1988; Mayer \& Anderson, 1991; Mayer \& Anderson, 1992; Mayer \& Sims, 1994).

\section{Fidelity of Animation}

Fidelity refers to the extent to which a graphic resembles reality (Alessi, 1988). That is, fidelity means the degree of realism in visual materials. The general assumption regarding fidelity of graphics is that increasing fidelity leads to a better learning experience due to the similarity of the instructional situation to the performance environment. However, the relationship between learning and fidelity is more complicated than this simple linear one. According to Alessi (1988), the relationship between the two (graphic fidelity and learning) relies heavily on the student's current instructional level.

As represented by figure 1 , the degree of realism should be based on the instructional level of the learner in order to provide an effective learning experience. 
Rieber (1994) states that "while it may be appropriate to provide experts with as realistic a [graphic] as possible, there appears to be optimal levels of fidelity for experienced and especially novice students. In other words, too much realism may cause more harm than good, especially for inexperienced students" (p. 228). Thus, instructional designers should consider that increasing fidelity does not always increase the student's learning and the fidelity effects depend largely on the instructional level of the student.

In general, the appropriate level of fidelity increases as a learner progresses. For example, the initial stages of instruction should employ simplified visuals in order to discriminate and highlight critical cues of the information. Removing unnecessary and irrelevant details of visuals may help novice students focus on the essential attributes of the information. In the later stages of instruction, more realistic visuals should be used in order to help transfer the information to the real-world environment.

Specifically, the fidelity level of the animation must be considered when cueing students' attention to motion and trajectory details contained in the animation. According to Salomon (1983, as cited by Rieber, 1990), "student perceptions of the amount of mental effort required by the instructional material are a critical factor in learning" (p. 139). Students who perceive material as being too difficult are likely to fail to process the material, because they are unwilling, or see themselves as unable, to learn. On the other hand, students who perceive material as too easy are likely to fail to process the material thoroughly or effectively. Animated visuals perceived by students 
as too easy quickly lose appeal, and animated visuals perceived as too demanding lead to frustration. Animated graphics which are too complicated or too simple for learners to understand fail to focus on desired learning objectives. Thus, when animation is used for instructional material, it is necessary for instructional developers to consider the appropriate level of fidelity of animation. The appropriate fidelity level can assist effectively cueing students' attention to motion and trajectory details contained in the animation.

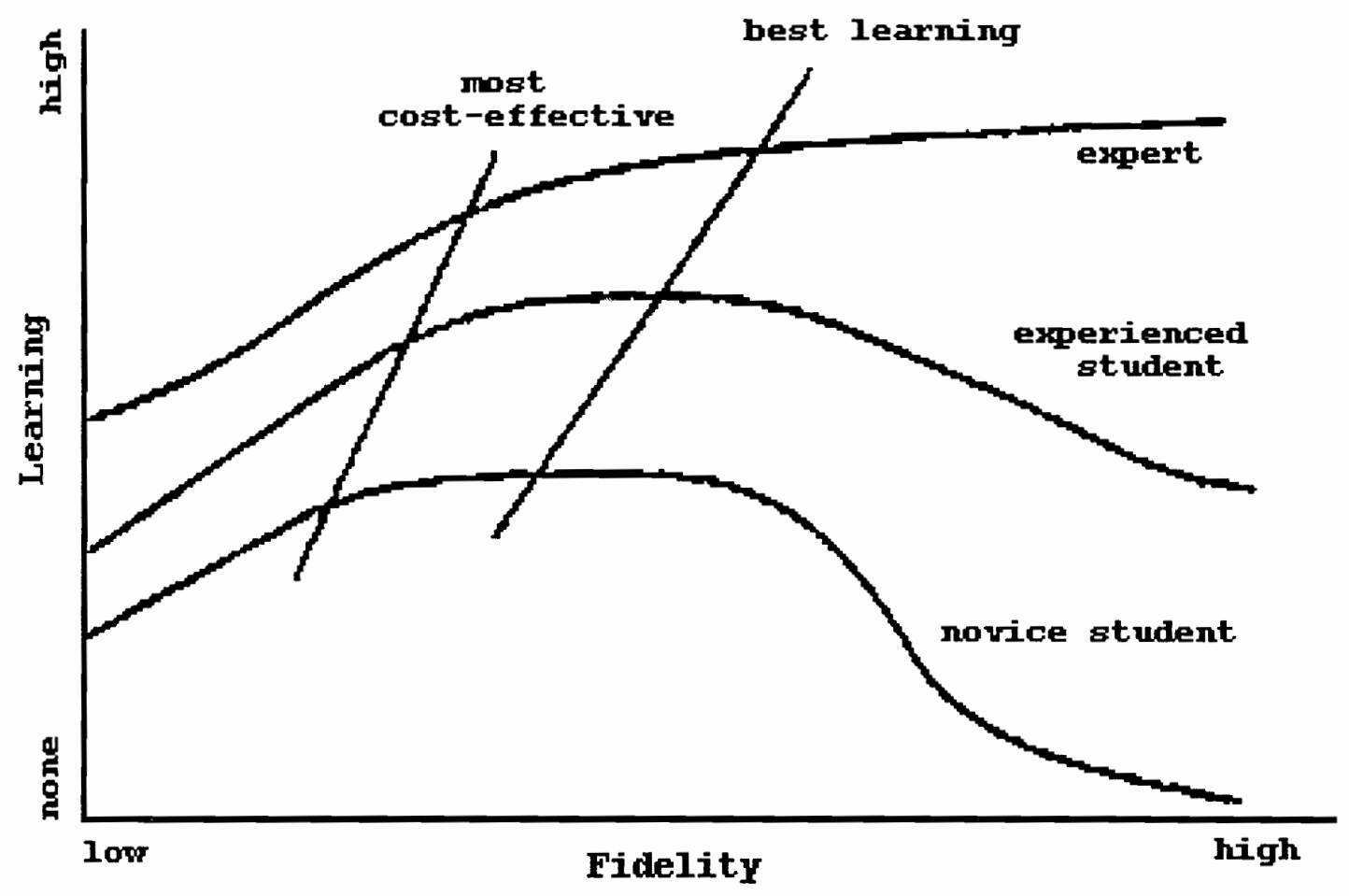

Figure 2. Hypothesized relationship of fidelity and learning (Alessi, 1988) 


\section{Learners}

The effectiveness of animation on the instructional process depends on the learner variable (Mayer \& Gallini, 1990). According to Mayer and Gallini (1990), animation is more appropriate and desirable when used with novices or inexperienced learners than experts or experienced ones. One possible reason for this differentiation is that learners who have considerable previous experience can easily visualize events, objects, or concepts from the verbal description provided in text. They are more likely to come to the lesson with existing mental images or the ability to rapidly build them (Mayer, 1989). Thus, it is not necessary for experienced learners to be exposed to animated visual images. Although one could argue that the inclusion of external visuals will probably do not harm, there exists the potential that unnecessary visuals may distract if they are used with learners who have considerable previous experience. Under such conditions, the added external visual is competing with the learner's mental image so that it may not facilitate the learner's performance (Rieber, 1994).

On the other hand, animated graphics become helpful and vital when learners lack previous experience and knowledge concerning to-be-learned objects, phenomena, or concepts. Animation becomes a necessary component in the instructional process for helping inexperienced learners bridge the gap between concrete experiences and symbolic representations of phenomena and events. Animation assists inexperienced learners in building effective, useful mental images. 
In short, low prior-knowledge and inexperienced learners, who lack skill in visualizing on their own, will be more likely to profit from animation-based instruction than expert and experienced learners.

In addition, there is some evidence to suggest that the effectiveness of animation on learning is also dependent on the user's age (Rieber, 1990; Rieber, Boyce, \& Assad, 1990). Research with adults have largely reported that maturation effects are involved in the process of building mental imagery. According to Pressley (1977), animation may not provide the same effectiveness on adult learners as children, because adults rely less on external images than children. Considering this maturation effect, it is assumed that providing adults with animated presentations may be unnecessary "when given verbal presentations which are carefully designed with highly imaginable explanations and when [they] are prompted to form ...internal images" (Rieber, Boyce, \& Assad, 1990, p. 51). However, based on response latency data of some of the research using adults, animation can provide important support, at least, for initial encoding and subsequent retrieval in adult learning (Rieber, 1990; Rieber, Boyce, \& Assad, 1990).

\section{$\underline{\text { Material }}$}

Because of the nature of science, to-be-learned science material needs to be "explanative" rather than "descriptive" (Mayer, 1989; Mayer \& Gallini, 1990; Mayer \& Sims, 1994). Explanative information provides relationships in a series of changes 
among parts of systems, objects, or events. That is, explanative material involves sequences which change one part of a connected part, which then results in a change in the next connected part, and so on. Thus, it is reasonable to assume that animated graphics, which convey the dynamic nature of information, are designed to teach such explanative information rather than narrative and descriptive information. If motion and trajectory attributes are not essential to understanding a certain concept or procedure, then animated visuals would not aid learning any more than static visuals. There is always the potential that unnecessary characteristics of motion and trajectory could be distracting in some way to the learner. Thus, a facilitating learning effect of animated visuals can be expected only when a task is based on explanative information involving changes over time or in a certain direction.

\section{Assessment Technique}

Instruction based on animation must employ appropriate assessment techniques to evaluate student progress (Mayer, 1989; Mayer \& Anderson, 1991; Mayer \& Gallini, 1990; Mayer \& Sims, 1994). The performance measures must evaluate the learner's understanding and qualitative reasoning about the material being presented, because animated visuals are likely to foster the learner's ability to build dynamic mental images. Learners who have built dynamic mental images are more likely to recall information about how one state change affects another, but they are less likely to remember irrelevant facts. In order to provide accurate data on the progress of 
learners through animated presentation, instruction based on animation must focus on assessment methods which measure students' understanding of relations and connections among the pieces of information.

\section{Words and Animation : Contiguity Principle}

A mapping between words and animation should be considered for students' effective learning. Mayer and Anderson (1991) state that "presenting verbal and visual explanations together in a coordinated way are more effective in promoting students' learning than are giving separate verbal explanations or visual explanation" (p. 484). There is consistent empirical evidence that the contiguity of verbal and visual explanations during instruction encourages learners to build connections between the verbal and visual representations of incoming information, which, in turn, support dual access into long-term memory (Mayer \& Gallini, 1990; Mayer \& Anderson, 1991; Mayer \& Sims, 1994). Preliminary research has also shown that animation, presented with accompanying narration, results in greater learning than when either is provided separately or when verbal representations are provided before or after the animated visuals (Mayer \& Anderson, 1991). Specifically, when the learning task presents facts, principles, or procedures involving motion and/or trajectory, it should be facilitated by instruction that provides adequate combinations of the visual and verbal means of these attributes to increase the likelihood of redundant encoding. Thus, instructional 
designers should stress the importance of corresponding captions or texts with animated visuals.

In short, for animation to have a positive effect on students' learning, the following conditions should be met: the difficulty of the animation must be appropriate; the target learners of animated presentations must be inexperienced and low-prior knowledge students; the to-be-learned material must be explanative rather than descriptive; the assessment method must focus on understanding causal relations and connections between information; and corresponding captions or texts must be provided along with animated presentations.

\section{$\underline{\text { Animation and Science Instruction }}$}

Traditionally, teaching the subject of science creates increasingly negative attitudes in students. According to Educational Testing Service (1988), the attitude toward science and the usefulness of science declined dramatically across the 9 to 17 year-old spectrum. Students have also shown little ability to solve transfer problems after successfully completing science class courses (Champagne \& Klopfer, 1984; Hoftstein \& Yager, 1982; Yager, 1989). One of the reasons for these negative results in science education may be that science teachers fail to provide appropriate instructional material which assists students in building conceptual mental models for understanding. 
Science deals mainly with causal relations and a series of movement or changes among parts of systems, objects, or events (Large, Beheshti, Breuleus, \& Renaud, 1995; Mayer, 1989). That is, many concepts and principles in science demand that the learner understand changes of a moving object at a certain speed (i.e., motion) or changes of a moving object in a certain direction (i.e., trajectory), or both (Mayer \& Anderson, 1991). Because animated materials direct students' attention toward the objects, locations, directions, and movement as well as the causal relations among actions, animation can be a useful and desirable tool for teaching students scientific explanations and concepts.

In addition, it is expected that if students are provided with animated presentations, they can construct dynamic images that they can mentally manipulate thus improving the ability to transfer what they have learned to solving new problems. There is consistent empirical evidence that animated science instruction facilitates students' solving transfer problems (Mayer \& Anderson, 1991; Mayer \& Anderson, 1992; Mayer \& Sims, 1994). Compared to text and static visual material, the ability to generate novel solutions to new problems is the most crucial benefit of animation in science instruction. Furthermore, the variety of colors and axes of motion in animated presentations can add realism and stimulate students' interest in the science subject. Animated material in science instruction has a strong potential for overcoming the decline in attitude towards science that has been especially prevalent among females. 
These studies related to animated science instruction suggest that animation can be a desirable tool or aid in facilitating students' learning of science, by providing information that is not available from other instructional materials.

\section{Cognitive Style}

Assessing and exploring the interaction of animation with other variables related to the learner's individual difference is an important dimension of this research. A considerable amount of research has dealt with the individual differences among learners in terms of cognitive style. Cognitive style generally refers to differences in the way an individual perceives and acquires information. Because visual-spatial ability affects how an individual will use visuals in instruction, it seems appropriate to consider these individual perceptual differences when developing and designing visual materials and to examine the effects of animated presentations on students' achievement across the cognitive styles known as field-dependence and fieldindependence.

\section{The Definition of Cognitive Style}

According to Witkin and his associates (Witkin, 1950; Witkin, Goodenough, \& Oltman, 1979; Witkin, Moore, Goodenough, \& Cox, 1977), a factor implicated in 
visual learning is the learner's degree of field-independence. They confirmed the two extremes of a continuum of the individual trait called field-dependence and fieldindependence which describes the way people perceive and process visual information. Through experiments dealing with participants' ability to perceive a part within a larger whole, they developed several tests to examine individual difference variables along perceptual lines: the Body Adjustment Test, the Rod and Frame Test, and the Embedded Figures Test. According to Halpern (1992), these tests are designed to access one of the following factors which visual-spatial ability is composed of: spatial perception and spatial visualization.

\section{Visual-Spatial Ability and Experiments}

\section{Spatial Perception}

This is an element of the visual-spatial ability which requires a person to locate the vertical while ignoring distracting information from a surrounding visual field (Halpern, 1992). The Body Adjustment Test and the Rod and Frame Test are used to find differences in this spatial perception of the upright position among individuals.

The Body Adjustment Test. Witkin and Asch (1948, cited in Witkin \& Goodenough, 1981) have conducted research in an attempt to explain the roles of the visual in perception of the upright position. In one of his experiments, the participants were seated in an adjustable chair in a darkened and tilted room. They were instructed 
to move the chair's position to an upright position, regardless of the room's orientation. It was found that there were considerable individual differences in adjusting the chair to the upright, but most people fitted one of the following two categories. Some individuals were able to locate the chair to its true upright position through body cues and sensation. Others depended on external visual referents, thus returning the chair in line with the tilted walls of the room. Witkin has defined the former individuals as field-independent and the latter as field-dependent. The result of the study suggests that people use two types of information to perceive the upright. People use cues from body sensation or rely on external environments cues such as corners of doors, rooms, and so forth (Witkin, Moore, Goodenough, \& Cox, 1977).

The Rod and Frame Test. The Rod and Frame Test was used in a subsequent experiment. This test was structurally similar to the Body Adjustment Test, only this test had a rod and frame instead a body and room. Both of these two tests asked the same question, that is "to what extent [is] perception of the item ... determined by the surrounding framework" (Witkin, Moore, Goodenough, \& Cox, 1977, p. 5).

The participants were placed in a darkened room and could see only an adjustable luminous rod and a luminous frame both of which were each tilted to a different angle. The participants were asked to move the rod to a position they perceived as upright. Again, while some people set the rod to its true upright position, others turned the rod in line with the tilted frame. The results confirmed that field- 
independent people relied on body referents, while field-dependent people tended to pay more attention to visual field cues to perception.

\section{$\underline{\text { Spatial Visualization }}$}

The Embedded Figures Test was developed to determine individuals' spatial visualization which requires "complex analytic multistep processing of spatial information" (Halpern, 1992, p. 68).

The Embedded Figures Test. Witkin and his associates (1977) subsequently developed the Embedded Figures Test, where the person tries to find hidden figures embedded in complex, geometrical drawings. This test detects the individual's ability to determine the extent to which he or she is influenced by the background or surrounding visual field. Again, the field-independent group's perception and judgment were independent of the appearance of the complex surrounding design, while the field-dependent group was more dominated by the competing field (Witkin, 1950; Witkin \& Goodenough, 1981; Witkin, Moore, Goodenough, \& Cox, 1977)

These three tests all share the common trait of measuring to what extent the surrounding visual field has influenced an individual's perception of an item within it. Witkin indicates that these tests have a high correlation to each other (Witkin \& Goodenough, 1981; Witkin, Moore, Goodenough, \& Cox, 1977). 


\section{Field-Dependence/Independence Effects on Learning}

The cognitive-style approach appears to have strong potential in producing the clearest promise and implications for a variety of educational issues (Witkin, Moore, Goodenough, \& Cox, 1977). There is considerable research that indicates a reliable influence of cognitive style on learning. Witkin and his associates (Witkin, 1950; Witkin \& Goodenough, 1981; Witkin, Goodenough, \& Oltman, 1979; Witkin, Moore, Goodenough, \& Cox, 1977) find individual differences in the learning approach between field-independent and field-dependent individuals.

Field-dependent individuals tend to be dominated by salient cues regardless of the relevance of those cues. They seem to have difficulty separating relevant items in the visual stimulus from the irrelevant surrounding visual. When a background or competing visual field is the most salient feature of the information, field-dependent learners rely heavily on those single prominent elements of a visual field. These learners fail to focus attention on critical and meaningful attributes out of the context in which the content is presented. They are likely to have difficulty distinguishing elements from background visuals and imposing a meaningful structure on the visual field, due to their lack of restructuring ability (Moore \& Dywer, 1991). According to Canelos, Taylor, and Gates (1980), the field-dependent learners have more difficulty acquiring spatial information than the field-independents. They say "this may have occurred because the acquisition of spatial information requires the restructuring of the stimulus situation since each part would be recalled in terms of its relation to the set of 
all possible parts" (Canelos, Taylor \& Gates, 1980, p. 68). Because field-dependents' acquisition of information relies heavily on external referents and salient features, their approach to learning is characterized as global compared to the articulated approach of field-independents (Witkin \& Goodenough, 1981; Witkin, Goodenough, \& Oltman, 1979; Witkin, Moore, Goodenough, \& Cox, 1977).

Field-independent learners are likely to focus attention on critical elements presented whether or not they are noticeable. They also tend to keep elements separate from the dominant competing visual field as presented. It appears that fieldindependent learners have an analytical approach to learning, with an ability to analyze and restructure visual information. This analytical cognitive approach makes it possible for field-independent learners to overcome the influence of competing context, while recognizing essential and relevant features (Witkin \& Goodenough, 1981; Witkin, Goodenough, \& Oltman, 1979; Witkin, Moore, Goodenough, \& Cox, 1977).

In Croft's dissertation (1995), he states that "the effect of field-dependence on the individual's ability to distinguish embedded features coupled with the tendency of field-dependents to focus on single prominent features rather than the articulated set of attributes represented has prompted an extensive quest for ways to improve learning for field-dependent students on assorted visual learning tasks" (p. 33). There exists a line of considerable research which attempts to examine and develop learning 
strategies and visual materials concerning the field-dependents' disadvantage of acquiring visual information (Dwyer \& Moore, 1992).

\section{$\underline{\text { Research on Effective Strategies for Field-Dependents }}$}

\section{Manipulating Instructional Materials}

In order to compensate for the weakness of field-dependent learners, instructional materials have been manipulated by using color coding and fidelity.

Color Coding. As new software makes it increasingly easy to use color in the development of visual materials, more and more color graphics are used in making appropriate discrimination and delivery of information. One body of work has addressed the influence of graphics with color coding on the performance of fielddependents. The possibility of interaction between color and field-dependence has been investigated based on the assumption that field-dependent learners are less likely to have difficulty getting visual information when visual materials are manipulated so that relevant cues are more salient and obvious.

Dwyer and Moore (1991), Moore and Dwyer (1991), Dwyer and Moore (1992), Moore and Dwyer (1994), and Dwyer and Moore (1994) have studied the effect of color coding on performance of students across levels of field-dependence. They used color cues to aid field-dependents in picking out essential information from 
visuals. The results state that field-dependents benefit from color emphasis on important parts of illustrations for visual learning objectives. Here are their results:

Research has shown that color coding helps learners organize or categorize information into useful patterns which enables the learners to interpret and adjust to their environment. Color coding may be considered a strategy which students enhance or sharpen essential message characteristics by providing structures for the storage of new information (Dwyer \& Moore, 1992, p. 312).

They conclude that "for some types of learning objectives the process of color coding instructional materials may reduce achievement differences attributed to differences in cognitive style" (Dwyer \& Moore, 1991, p. 677).

Although, there is some evidence that color can enhance learning by fielddependents, there is always a danger that misused color may be ineffective or even detrimental. Thus, before any color is employed for field-dependents, a need for "color discrimination" must be established. If there is a case that color can be very effective for distinguishing different parts of graphics or for emphasizing critical attributes, then less color should be used for effective attraction of attention (Merrill \& Bunderson, 1981). Too many colors should be avoided because they make visual materials 
ambiguous and distracting. Also, color should be used to direct attention of fielddependent learners only to critical features of the information.

In short, color can facilitate learning by field-dependents when it is used to highlight relevant cues and to aid in making appropriate discriminations.

Fidelity or Visual Complexity. Considerable research has also been conducted on the effects of illustration complexity on learning. According to Wise (1984), there exist two lines of research in this area. One group believes that learning improves when visuals are realistic and detailed. Researchers of this group support that additional cues in illustrations increase and facilitate students' learning (Gibson, 1954; Knowlton, 1964). On the other hand, another group contends that the increased amount of realism has a distracting effect on students' learning, thereby complicating the visual information processing (Alessi, 1988; Canelos, Taylor, \& Gates, 1980; Dwyer, 1972; Merrill \& Bunderson, 1994). They argue that visuals which are either too complex or realistic can cause the learner difficulty in perceiving and distinguishing the features of the graphics that are critical to appropriate classification and understanding. They have found that learning increases when visuals become simple and uncomplicated.

A number of researchers have addressed the influence of fidelity of illustration on learning of field-dependents or field-independents by using visual materials for a heart lesson developed by Dwyer (Canelos \& Taylor, 1981; Canelos, Taylor, \& Dwyer, 
1985; Canelos, Taylor, \& Gates, 1980; Dwyer, 1967, 1978). Results of most studies show that an increased amount of realism is not necessary to increase students' achievement. This research has stated that simplified visual materials (e.g. simple linedrawing) are more effective for learning than complex visual materials (e.g. photographs).

In general, the number of irrelevant cues is reduced and the number of relevant cues is increased in simplified instructional visuals. That is, simplicity of visuals tends to emphasize the important parts so that visual materials become clearer, easier, and more structured for field-independent learners to interpret. Removing unnecessary and irrelevant details from visual materials can help the field-dependent learner to isolate and highlight critical attributes and features of the information. Thus, it is a reasonable assumption that simplified visual materials aid field-dependents in making appropriate discriminations of relevant cues from competing irrelevant ones. Although it is generally believed that simplified visuals enhance learning, the development of instructional visuals should be based on the consideration that the effect of visual complexity on learning depends on several variables such as learners' experience, learning task and so forth.

\section{Training Restructioning Ability}

According to Clark and Salomon (1986), most research concerning interaction between learning and cognitive styles has mainly dealt with manipulating visual 
materials, rather than training restructional skills of the learner. Rush and Moore (1991) state that "there is little research regarding the effectiveness of attempting to teach field independent restructuring strategies to those field-dependent individuals who characteristically lack the ability to restructure" (p. 309). They believe that although manipulating instructional materials is likely to be effective in a certain context, such effect would not be transferred to new learning tasks. Lawson and Wollman (1976) also assert that the effectiveness of designing visual materials is limited by context without any transfer effect.

One piece of research which concentrated on teaching restructional strategies was conducted by Rush and Moore (1991). The purpose of the study was "to examine the possibility of identifying restructuring strategies among field independent learners and teaching these strategies to field dependent learners." The result of the study shows that "training enhanced field dependent subject performance on two dependent measures tasks" (Rush \& Moore, 1991, p. 309). Also, this study reveals an interaction between treatment (training vs. no training) and cognitive styles (field-dependence vs. field-independence) on three tests (the Hidden Figures Test, the Group Embedded Figures Test, and the Scrambled Words Test).

However, a question arises as to how far and how much such training would compensate for disadvantages and weaknesses of field-dependent learners. Generally, it is assumed that training has little and limited effect on learning of field-dependents. McCloy and Koonce (1982) hold that it is not known whether the person who received 
the training will be able to transfer their restructuring and spatial ability to other new and different tasks. This still remains an important question in future research concerning the effect of training restructional ability on field-dependent learners.

\section{Gender Differences and Degree of Field-Dependence}

Several studies have indicated that different cognitive styles exist between men and women (Witkin, 1981; Witkin, Dyk, Faterson, Goodenough, Karp, 1962; Witkin, Lewis, Hertman, Machover, Meissner, Wapner, 1972). Each gender tends to have its own unique characteristics concerning perception and learning. In general, females are more field dependent than males. Women's field dependence has been described as global and passive in their approach to acquiring visual information, while men's field independence is as analytic and active in processing information (Witkin, 1981; Witkin, Dyk, Faterson, Goodenough, Karp, 1962; Witkin, Lewis, Hertman, Machover, Meissner, Wapner, 1972). The usual findings of gender differences in field dependence are that women may be less able to overcome the influence of the context than men. Women are likely to be more influenced by salient features. They have difficulty analyzing and restructuring visual information when dominant cues are not relevant for information processing. Halpern (1986) states that "because women are unable to maintain a sense of separate identity, they are less skilled at certain types of problem solving, more likely to conform to group pressure, and more concerned with the facial expressions of others. Thus, different cognitive styles have been ascribed to 
men and women on the basis of their performance on the cognitive tests (p. 55)." A possibility exists that gender differences in cognitive styles may be one of reasons for the low interest and participation of women in science (Bar-Haim \& Wilkes, 1989).

\section{Field-Dependent Learners and Science Instruction}

In general, teaching the subject of science creates increasingly negative attitudes in students. Many believe science classes have remained boring and uninteresting. As a result, many students have been alienated from science, most notably females (Hoftstein \& Yager, 1982; Yager, 1989). Females who use the global cognitive approach to learning may be less skilled at analytical or scientific types of problem solving because learning of this type requires the ability of analyzing and restructuring in perceptual and intellectual domains (Bar-Haim \& Wilkes, 1989; Halpern, 1986).

However, these proposed gender differences in scientific understanding could be overcome with appropriate cueing strategies which make it possible for females with field-dependence to compensate for their weaknesses on perception. One such strategy might be animation treatment in science instruction. 


\section{Animation: An Effective Cueing Strategy for Field-Dependents in Science Education}

In science classrooms, animation tends to be especially helpful for fielddependent learners in acquiring and processing knowledge from visual materials by effectively cueing student attention to the essential items of visual materials. Fielddependent learners are likely to experience difficulty in distinguishing, recognizing, and analyzing relevant cues from the irrelevant competing background. The emphasis on essential parts of visuals using motion and trajectory would make the relevant cues more salient and obvious to field-dependent learners and aid those individuals in overcoming the influence of an irrelevant context. The adequate use of the special effects of animation might be able to make the learning task in science become clearer, easier, and more structured for field-dependent learners to perceive the essential messages of the learning task.

\section{Summary and Hypotheses}

For the past few years, there have been increasing efforts to fully use the recent advances of computer technology, including animation, sound, and video in instruction (Rieber, Boyce, \& Assad, 1990). Especially, as new software for computers makes it increasingly easy to produce animation, more and more instructional designers incorporate the animation feature into educational programs and materials. Although 
it is generally believed that the unique attributes of computer animation facilitates students' learning, there must be special efforts to build rational and theoretical support concerning the way in which students learn from the new feature, "animation" (Rieber, 1990). Before employing animation as a tool or aid in the instructional process, instructional designers must examine theoretical and empirical justification of the effectiveness of animation in the teaching and learning processes.

From both theoretical and practical points of view, the effectiveness of animation on students' learning was reviewed in this study. Because animation offers two unique perceptual attributes, motion and trajectory (Rieber, 1990), it has been shown that animated visuals are most effective when these two attributes are suitable for the demands of the instructional task, such as those frequently found in science instruction. Because learning tasks in science demand that the learner understand changes of an object over time or in a certain direction, animation can make such changes more vivid and distinguished by showing motion and trajectory directly to learners. Because these attributes of animation aid learners in making appropriate discrimination between relevant and irrelevant cues of the information, animation would increase the potential for successful learning of field-dependent learners who have difficulty perceiving and processing visual-spatial information.

In short, animation can be considered as the most desirable and effective tool in facilitating students' learning on scientific concepts, especially for field-dependent learners. The purpose of this study then is to explore the attributes of animation and 
their relationships to the cognitive style of field-dependent-independent in science instruction. That is, this study is to examine the effectiveness of animation in the enhancement of understanding and retention of scientific concepts in computer-based modules across learners possessing different cognitive style. Thus, this study is designed to provide empirical data concerning the predictions of the following research hypotheses that emerged from this literature.

$\mathbf{H}_{\mathbf{1}}$ : On both problem-solving and recall tests of scientific concepts, students receiving an animation treatment will perform better than those receiving a static graphic treatment.

$\mathbf{H}_{\mathbf{2}}$ : On both problem-solving and recall tests of scientific concepts, field-independent students will perform better than field-dependent students .

$\mathbf{H}_{3}$ : On both problem-solving and recall tests of scientific concepts, there will be interaction between the treatment group (animation and static graphic) and the cognitive style category (field-independent and field-dependent).

The last hypothesis suggests a significant treatment $\times$ trait $\times$ task interaction. Specifically, the following interaction is predicted :

On both problem-solving and recall tests of scientific concepts, field-independent students will perform better than field-dependent students in the static graphic group, but not in the animation group. 


\section{CHAPTER III}

\section{METHODOLOGY}

This chapter discusses the following four aspects of the methodology used in the research: (1) the participants involved in the experiment; (2) the research design including the independent and dependent variables and the statistical procedures used to analyze the data; (3) the materials and apparatus used while conducting the experiment; and (4) the procedure applied for the data collection.

\section{Participants}

Participants for this study were 121 undergraduate and graduate students at the Virginia Polytechnic Institute and State University. The participants were involved in this study on a voluntary basis. Through the permission of five faculty members of the College of Human Resources and Education, the researcher had access to students in their classrooms, in order to explain the purpose of the study, the importance of the study, the procedures to be used in the study, and to recruit volunteers.

Participants were given a questionnaire designed to assess their level of prior experience with mechanical items. Only those participants who reported low levels of prior knowledge about mechanical devices were included in the experiment. That is, 
participants who reported more than novice-level experience with mechanical items were excluded from this investigation. Of the 169 participants in the study, 48 participants were eliminated, leaving 121 novice-level participants. At the site of the experiment, each novice-level participant was assigned randomly to one of two treatments that will be described in the following section.

\section{Research Design}

A $2 \times 3$ factorial design (presentation type $\times$ level of field-dependence) was used in this study (see Figure 3). A two-way analysis of variance (ANOVA) was used to analyze the data. The level of statistical significance for all procedures used in this study was set at $\mathrm{p} \leq .05$.

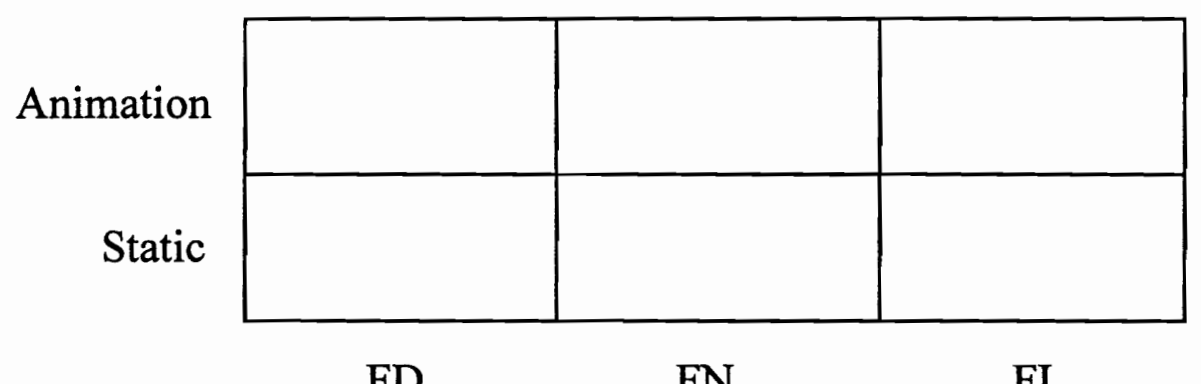

Figure 3. $2 \times 3$ Factorial Research Design 
The posttest only research design was chosen in this study because this design is strong in both internal and external validity. A pretest was not included in this experiment, because exposure to a pretest may affect the participants' performance on a posttest and such practice effects can lead to alternative interpretations of the findings. This study also used random assignment in order to provide adequate control of extraneous variables and appropriate generalization of the findings.

Presentation type (animation, static graphic) and cognitive style (fielddependent, field-independent) were the independent variables in the study. The dependent variables were the problem-solving and retention as measured by the problem-solving test and the recall test respectively.

\section{Materials \& Apparatus}

\section{Computer-Based Materials}

The computer-based materials consisted of the two experimental treatment programs: animation and static visuals. These materials represented an animation or static graphics of the operation of a bicycle tire pump. The animation and static graphics portrayed a line drawing of a bicycle tire pump, including handle, rod, piston, cylinder, inlet valve, outlet valve, and hose. Both conditions depicted the information that "(a) a handle that moves up and down, (b) a piston that moves up and down, (c) an inlet valve that opens and closes, (d) an outlet valve that opens and closes, (e) a 
cylinder that contains compressed or uncompressed air, and (f) a hose that contains or does not contain air (Mayer, 1992, p. 394). In both conditions, air was represented by a shaded region of black dots and the movement by arrows.

The following text was narrated in both of the computer presentations. The narration was explanative information describing how a change in the status of one part affects changes in the status of other parts.

When the handle is pulled up, the piston moves up, the inlet valve opens, the outlet valve closes, and air enters the lower part of the cylinder. When the handle is pushed down, the piston moves down, the inlet valve closes, the outlet valve opens, and air moves out through the hose.

The computer presentations were written in Director 4.0. Animation of a bicycle pump was mainly constructed in Director 4.0. Static visuals of a bicycle pump were developed in Fractal Design Painter 4.0. Narration for both presentations were recorded with SoundEdit 16.

\section{Paper-and-Pencil Materials}

The paper-and-pencil materials included a questionnaire, the Group Embedded Figures Test, one problem-solving test sheet, and one recall test sheet. 


\section{The Questionnaire}

The purpose of this questionnaire was to determine the participants' level of knowledge about mechanical devices. The questionnaire used in this study was the same developed and used by Mayer in his 1994 study on animation (see Appendix B). This questionnaire contained two types of questions. The first question asked each participants to "put a check mark next to the things you have done" for a list of six statements related to mechanical activities. Each check mark counted as one point. The second question asked participants to "put a check mark indicating your knowledge of how to fix household appliances and machines" on a 5-point scale ranging from very little (1) to very much (5). Participants who scored 5 or more in this questionnaire were determined to be of high prior-knowledge level. Those participants were eliminated from the experiment.

\section{The Group Embedded Figures Test}

The Group Embedded Figures Test was used to classify the participants as field-dependent, neutral, or field-independent (Witkin, et al., 1971). This test determined the participants' ability to find a simple geometric figure embedded within a more complex figure. The test consisted of three sections of 7,9 , and 9 items. The time limit was set as 2,5 , and 5 minutes for each section respectively. The score can range from zero to 18 . 
The participants were assigned to one of three categories based on their scores. Students who scored one-half standard deviation above the mean were classified as field-independent and those who scored below one-half standard deviation the mean were classified as field-dependent. Participants located in the middle were classified as neutral. This criteria was the same used in Moore and Dwyer's 1991 study (Moore \& Dwyer, 1991)

\section{The Problem-Solving Test}

The problem-solving test used in this study was the same one developed by Mayer for his series of studies on animation in 1991, 1992, and 1994 (see Appendix C). The problem-solving test contained the following questions: "What could be done to make a pump more reliable, that is, to make sure it would not fail?"; "What could be done to make a pump more effective, that is, to move more air more rapidly?"; "Suppose you push down and pull up the handle of a pump several times but no air comes out. What could have gone wrong ?"; and "Why does air enter a pump?, Why does air exit from a pump?" These questions were designed to evaluate the learner's understanding of the material. Only those participants who build an accurate and usable mental model of the to-be-learned materials can appropriately answer to this problem-solving test, because they can easily run, manipulate, and apply their mental model corresponding to each new problem situation. 
Scoring. Each participant's performance on the problem-solving test was scored by two judges who were not aware of the students' treatment condition. Participants were given one point for each acceptable answer for these questions, with a maximum four points on each of questions one, two, three, and a maximum of two points on question four. Acceptable answers for each question were obtained from both experts in the field of engineering and Mayer's studies in 1991, 1992, and 1994. Examples of acceptable answers were following: (a) press or pull the handle harder and faster or use a large size of cylinder, (b) use airtight seals, (c) check a hole or a stuck valve in the pump, and (d) suction or vacuum accounts for air entering the cylinder and compression accounts for air exiting the cylinder.

\section{The Recall Test}

This study employed the same recall test developed and used by Mayer for his series of studies on animation in 1991, 1992, and 1994 (see Appendix C). The recall test included the following question: "Write down an explanation of how a bicycle tire pump works. Pretend that you are writing to someone who does not know much about pumps." The test was developed to evaluate the conceptual recall of information about how one state change affects another. Participants who focus on relevant and essential information about the bicycle pump mechanism can appropriately answer the recall test which requires the participants to retain a series of changes and connections among the pieces of information. 
Scoring. In order to score participants' responses on the retention test, a list of acceptable responses was established as follows : (1) handle is pulled up, (2) piston moves up, (3) inlet valve opens, (4) outlet valve closes, (5) air enters cylinder, (6) handle is pushed down, (7) piston moves down, (8) inlet valve closes, (9) outlet valve opens, and (10) air exits through hose. Referring to this checklist which was broken into ten idea units, scorers gave credit if an idea unit in the student's written answer conveyed the same meaning as an idea unit in the established checklist. The total score was determined based on the number of idea units that were included in each participant's answer to the recall test. The maximum was ten points for this test.

\section{Procedure}

After participants signed a consent form, they had five minutes to complete the questionnaire rating their level of experiences with the mechanical devices and twelve minutes to take the Group Embedded Figures test determining their levels of fielddependence. Participants who obtained a score of five or above in the questionnaire were eliminated from the experiment. Only novice-level participants were then randomly assigned to either animation or static graphic treatment groups. Each participant was seated in front of a separate computer and viewed the bicycle pump presentation corresponding to their treatment group assignment. Each presentation began by instructing participants to click on the mouse to receive the presentation. 
Upon clicking the mouse, participants viewed the animated or static visual presentation about how a bicycle pump operates. Participants viewed the presentation three times, with each presentation lasting 30 seconds for both the animation and static visual groups. The computer presentations were terminated by informing the participants that "Please tell your assistant that you are finished." After finishing the presentation, the participants completed the problem-solving and recall test. They were allowed ten minutes on the problem-solving test and five minutes on the recall test (see Figure 4).

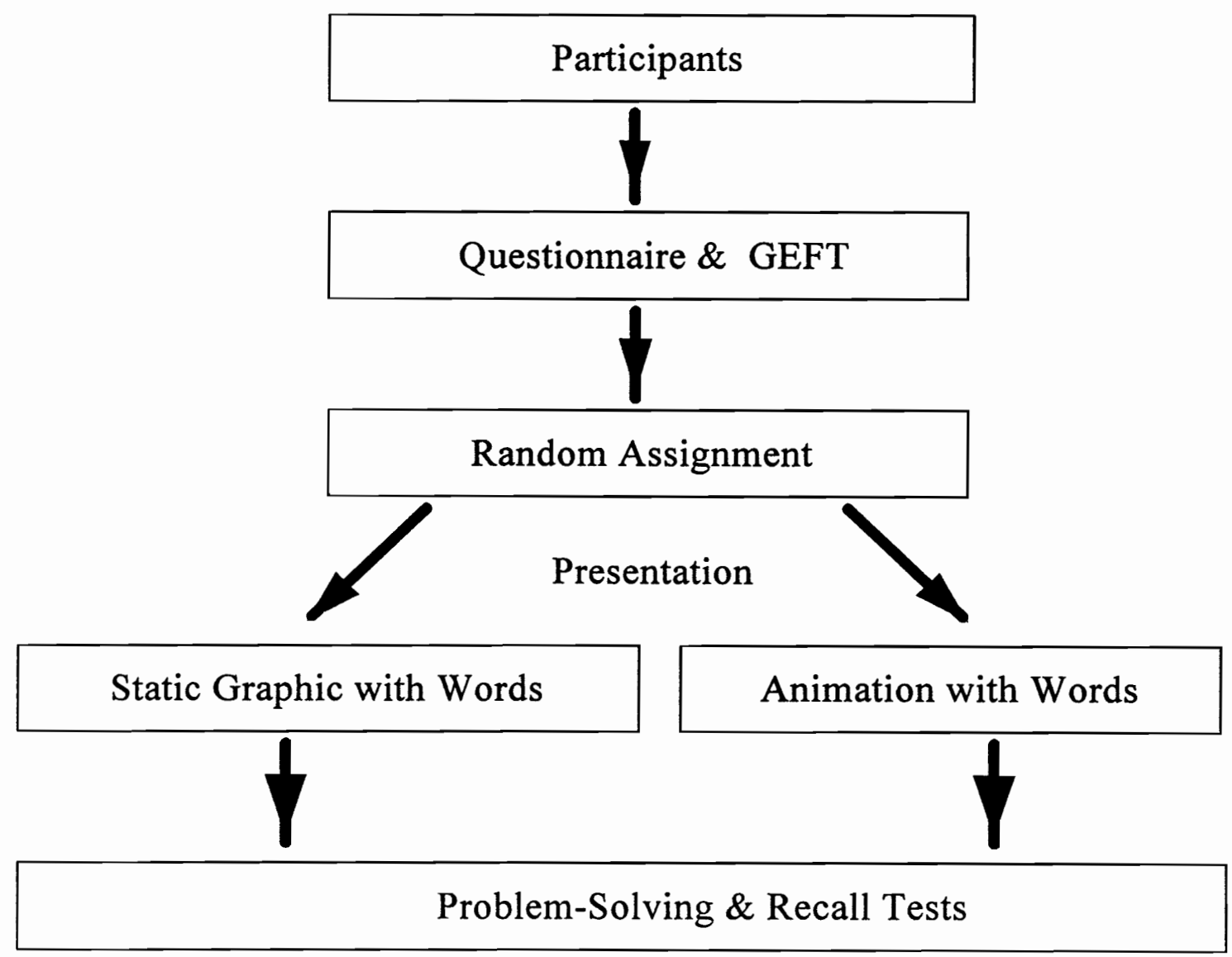

Figure 4. Research Procedure 


\section{Pilot Study}

A pilot study was undertaken to make adjustments to the procedure and materials through executing a trial run of the experiment. Specifically, the study focused on whether two posttests used in this investigation, problem-solving and recall tests, could provide enough score variance for conducting data analysis.

This study was carried out during the summer of 1996, with 24 volunteers from the Instructional Systems Development program at the Virginia Polytechnic Institute and State University. The participants were told that they were participating in a pilot study and would be individually interviewed after the study to gather their feedback. The purpose and the procedure of the study were also explained to them. Twelve of the participants were offered the animation treatment while the remaining twelve participants were offered the static visual treatment. After they viewed one of the presentations, that is animation or static visual, they completed two posttests, problemsolving and recall tests.

Some revisions in the format of the presentation and procedures were made based on the result of the study and the feedback from the participants. The review of the data from the study revealed that there was enough score range on both problemsolving and recall tests to provide variance. As a result of this pilot study, it was confirmed that both posttests were acceptable in terms of score variance for data analysis. 


\section{CHAPTER IV}

\section{RESULTS}

This chapter provides the results of testing the research hypothesis presented in the Chapter Two. A description of the obtained data and the results of the inferential statistical test will be reported in the following section.

\section{Data Description}

A total of 169 participants was involved in the experiment. On the basis of the questionnaire rating their level of prior experience with mechanical items, 48 participants who reported more than novice-level experience were excluded from this investigation. Thus, the data from 121 novice-level participants were included in the statistical procedures.

The participants were identified as field-dependent, field-neutral, or fieldindependent on the basis of their scores on the Group Embedded Figures Test (GEFT). The mean and the standard deviation scores of the GEFT were 12.20 and 4.40 respectively. Students who scored in the range of the mean plus and minus one-half standard deviation were classified as field-neutral (10-14); those with scores of above this range were regarded as field-independent (15-18); and those with scores below the range were considered as field-dependent (0-9). Each of the participants in the three 
categories were randomly assigned to two treatment groups, animation $(n=61)$ or static visual $(n=60)$. The means and standard deviations of students' problem-solving and recall scores per treatment are presented in Table 1.

Table 1 Means and Standard Deviations of Students' Scores on the ProblemSolving and Recall Tests per Treatment

\begin{tabular}{|c|c|c|c|c|c|c|}
\hline \multirow[t]{2}{*}{ Treatment } & \multirow[t]{2}{*}{ Cognitive Style } & \multirow[t]{2}{*}{$n$} & \multicolumn{2}{|c|}{ Problem-Solving } & \multicolumn{2}{|c|}{ Recall } \\
\hline & & & $M$ & $S D$ & $M$ & $S D$ \\
\hline \multirow[t]{3}{*}{ Animation } & Field-Independent & 25 & 6.24 & 1.96 & 8.40 & 1.00 \\
\hline & Field-Neutral & 20 & 5.90 & 1.41 & 7.35 & 1.39 \\
\hline & Field-Dependent & 16 & 5.25 & 1.80 & 7.63 & 1.45 \\
\hline \multirow[t]{3}{*}{ Static Visual } & Field-Independent & 22 & 5.64 & 2.13 & 8.41 & 1.53 \\
\hline & Field-Neutral & 20 & 4.30 & 1.42 & 7.00 & 2.27 \\
\hline & Field-Dependent & 18 & 3.78 & 1.11 & 6.28 & 2.59 \\
\hline
\end{tabular}




\section{Analyses}

A $2 \times 3$ analysis of variance (ANOVA) was used to test the research questions concerning the type of presentation and type of cognitive style. Due to the unequal sample sizes across cells, it was judged more appropriate to test the null hypotheses using the unequal n's analysis of variance. As a result, the data analysis was conducted based on the adjusted mean scores for unequal n's analysis of variance.

The independent variables were cognitive style (field-independent, fieldneutral, or field-dependent) and presentation type (animation or static visual). The independent variables of presentation type and cognitive style were tested across each of the two dependent measures, problem solving and recall tests. A summary table of the $2 \times 3$ analysis of variance conducted on problem-solving and recall test scores are reported in Appendix A. 


\section{Primary Analysis}

Hypothesis One: Students receiving an animation treatment will perform better than those receiving a static graphic treatment on both problem-solving and recall tests of scientific concepts.

Analysis of $F$-test reveals that participants in the animation group $(M=5.87)$ did perform significantly better than participants in the static visual group $(M=4.63)$ on the problem-solving test $\left(F(1,115)=15.34, M S_{e}=44.52, p<.05\right)$; while participants in the animation group $(M=7.85)$ did not score significantly higher than participants in the static visual group $(M=7.30)$ on the recall test $(F(1,115)=3.06$, $\left.M S_{e}=9.39, p>.05\right)$. Thus, this hypothesis was confirmed on the problem-solving test but not on the recall test. Table 2 presents the means and standard-deviations by group for each of two dependent measures.

Table 2 Means and Standard Deviations by Group on the Problem-Solving and Recall Tests

\begin{tabular}{c|c:c|c|cc}
\hline Presentation Type & $n$ & \multicolumn{2}{|c|}{ Problem-Solving } & \multicolumn{2}{|c}{ Recall } \\
& & $M$ & $S D$ & $M$ & $S D$ \\
\hline Animation & 61 & 5.87 & 1.78 & 7.85 & 1.33 \\
Static visual & 60 & 4.63 & 1.80 & 7.30 & 2.29 \\
\hline
\end{tabular}


Hypothesis two: Field-Independent students will perform better than field-dependent students on both problem-solving and recall tests of scientific concepts.

Analysis of $F$-test reveals that field-independent participants did perform significantly better than field-dependent participants on both problem-solving ( $F$ ( 2 , $\left.115)=7.14, M S_{e}=20.71, p<.05\right)$ and recall $\left(F(2,115)=8.43, M S_{e}=25.88, p<\right.$ $.05)$ tests. The mean scores of the field-independent group $\left(M_{\text {problem }}=5.96, M_{\text {recall }}=\right.$ 8.40) significantly differed from those of the field-dependent group $\left(M_{\text {problem }}=4.47\right.$, $\left.M_{\text {recall }}=6.92\right)$ in favor of field-independent students on both problem-solving and recall. Table 3 below shows the compared means of field-dependent and fieldindependent participants on the problem-solving and recall tests.

Table 3 Means of Field-Independent, Field-Neutral, and Field-Dependent Participants on the Problem-Solving and Recall Tests

\begin{tabular}{c|c:c:c:cc}
\hline Presentation Type & $n$ & Problem-Solving & \multicolumn{2}{|c}{ Recall } \\
& & $M$ & $S D$ & $M$ & $S D$ \\
\hline Field-Independent & 47 & 5.96 & 2.04 & 8.40 & 1.26 \\
Field-Neutral & 40 & 5.10 & 1.61 & 7.18 & 1.87 \\
Field-Dependent & 34 & 4.47 & 1.64 & 6.92 & 2.21 \\
\hline
\end{tabular}


Hypothesis three: On both problem-solving and recall tests of scientific concepts, there will be interaction between treatment group (animation and static graphic) and cognitive style category (field-independent and field-dependent).

The resulting $F$ statistic was not significant for the interaction effect between two independent variables, the type of presentation and cognitive style, on both problem-solving $\left(F(2,115)=1.20, M S_{e}=3.19, p>.05\right)$ and recall $(F(2,115)=1.52$, $\left.M S_{e}=4.67, p>.05\right)$ tests.

\section{Planned Comparison}

Secondary analyses were planned to examine whether animation could reduce the difference between the two cognitive style groups. Specifically, the purpose of the secondary analyses was to investigate the possibility of minimizing the differences between field-independents and field-dependents by using an animated visual treatment. A series of one-way analyses of variance (ANOVA) were used to investigate such animation effect on the field-dependence-independence differences.

The first one-way ANOVA attempted to assess achievement differences occurring between field-independents and field-dependents when students received only the animation or static visual treatment. No differences in problem-solving performance were found between field-independent $(M=6.24)$ and field-dependent 
$(M=5.25)$ students who received the animated visual treatment, $F(2,58)=1.55, M S_{e}$ $=4.80, p>.05$; while significant differences were found between field-independents $(M=5.64)$ and field-dependents $(M=3.78)$ who received static visual treatment, $F(2$, $57)=6.93, M S_{e}=18.77, p<.05$.

However, when a similar comparison was conducted on the recall test among these students who received only animated visual or static visual, significant differences were found between field-independent and field-dependent students in both animation $\left(F(2,58)=4.20, M S_{e}=6.69, p<.05\right)$ and static visual $(F(2,57)=$ $\left.5.21, M S_{e}=23.84, p<.05\right)$ groups in favor of field-independent students. The mean scores of the animation group on recall were 8.40 and 7.63 for the field-independents and field-dependents respectively; the mean scores of the static visual group were 8.41 and 6.28 for the field-independents and field-dependents respectively (see Table 1).

In order to confirm the above findings on the field-dependent participants' benefit from animated visual treatment, another secondary analysis was conducted using one-way ANOVA in which only field-dependent students' performances were involved. The one-way ANOVA revealed that differences between the animation treatment group $(M=5.25)$ and static visual treatment group $(M=3.78)$ on the problem-solving test were statistically significant $\left(F(1,31)=8.38, M S_{e}=18.36, p<\right.$ $.05)$; while there were no reliable differences between the animation $(M=7.63)$ and static visual $(M=6.28)$ treatment groups on the recall test $\left(F(1,31)=3.38, M S_{e}=\right.$ 
15.38, $p>.05)$. The means and standard deviations of field-dependent participants' scores per each treatment are presented in Table 4.

Table 4 Means and Standard Deviations of Field-Dependent Participants' Scores per Each Treatment on the Problem-Solving and Recall Tests

\begin{tabular}{|c|c|c|c|c|c|}
\hline \multirow[t]{2}{*}{ Presentation Type } & \multirow[t]{2}{*}{$n$} & \multicolumn{2}{|c|}{ Problem-Solving } & \multicolumn{2}{|c|}{ Recall } \\
\hline & & $M$ & $S D$ & $M$ & $S D$ \\
\hline Animation & 16 & 5.25 & 1.81 & 7.63 & 1.46 \\
\hline Static visual & 18 & 3.78 & 1.11 & 6.28 & 2.59 \\
\hline
\end{tabular}




\section{CHAPTER V}

\section{SUMMARY, DISCUSSION, AND CONCLUSION}

\section{Summary}

Advances in computer technology have made it possible for educators to design and develop their own multimedia instructional materials using visuals such as animation. Although it is generally believed that the new attributes of computer animation facilitates students' learning, there is still relatively little research regarding the way in which students benefit from multimedia instruction using animation. Moreover, existing educational research literature has shown inconsistent results of benefits of animation in the learning process. As a result, additional studies of animation, are required to investigate this discrepancy to confirm the animation effect.

The purpose of this study was to examine and provide such theoretical and empirical justification of the effects of animation in the learning process. Specifically, the purpose of this study was to investigate the effectiveness of animation in the enhancement of the problem-solving and retention of scientific concepts in computerbased modules across learners possessing different cognitive style. This study extended traditional research on animation by adding a new independent variable named "learners' cognitive styles", highlighting the role of individual differences among learners. This study attempted to show the possibility of compensation for the 
weakness of field-dependents learners who have difficulty acquiring visual information by manipulating instructional materials using animation.

In this study, two computer-based presentation materials were developed in animation and static visual formats. Each instructional presentation illustrates how a bicycle pump operates. The participants' learning outcomes were measured by tests of the problem-solving and retention of the material given in the experiment. Both problem-solving and recall posttests were conducted immediately after the completion of each presentation.

Three research hypotheses were developed in this research based on a review of research literature. The first hypothesis stated that students receiving an animation presentation will perform better than those receiving a static visual presentation. The second was that field-independent participants will score better than field-dependent participants on problem-solving and retention of scientific concepts. The third reflecting the interaction between two variables, presentation type and cognitive style, was expected to show the effect of animation on the achievement of students who possess different types of cognitive styles.

These research hypotheses were tested using a two-way analysis of variance for unequal sample size at the .05 level of significance. A $2 \times 3$ factorial research design was used in which the independent variables were the presentation type and the cognitive style and the dependent variables were the problem-solving and retention of the material presented. Planned comparison, a series of one-way analysis of variance, 
were conducted to examine whether animation could compensate for the differential achievement that occurred between field-independents and field-dependents. A discussion of results detected from these analyses are provided in the following section.

\section{Discussion}

The first research hypothesis, that students receiving an animation treatment would perform better than those receiving a static graphic treatment, was confirmed for problem-solving but not recall of scientific concepts. In fact, participants in the animation group actually generated about $30 \%$ more correct answers on the problemsolving test than did participants in the static visual group. This result agreed with the findings of Mayer's series of research $(1991,1992, \& 1994)$ and Williamson and Abraham's research (1995). Because the learning task chosen in this experiment (e.g. learning bicycle pump operation) requires participants to understand ideas involving changes over time or in a certain direction, animated visuals which showed this motion and trajectory directly to participants, may have helped reduce the level of abstraction of such learning tasks and increase the learners' potential for development of accurate dynamic mental model on the bicycle pump mechanism. Students who successfully built such a mental model might more easily run and manipulate their dynamic mental model corresponding to each problem situation. Thus, the participants in the animated 
group more effectively transferred what they learned from the presentation to new situations, resulting in their higher achievement in the problem-solving test given in this experiment than their counterparts in the static visual group. Static visuals, however, only enabled students to mentally construct the dynamic parts of images of how a bicycle pump operate on their own. This caused an increase in the level of abstraction of the learning task. Because static visuals failed to depict the dynamic nature of many of the processes of such an instructional task, the static visual group students might not form an appropriate dynamic mental model which they could manipulate to novel situations. Thus, students' performance in the static visual group on problem-solving did not approach the level of performance for students in the animated group.

The first prediction that the animated visual group would perform better than the static visual group was not confirmed for recall of scientific concepts. Although earlier findings had indicated that animation might increase recall performance (Kobayashi, 1986), the results of this research are consistent with the findings of Mayer's (1991, 1992, \& 1994) series of studies and Large's study (Large, Beheshti, Breuleus, \& Renaud, 1995), in which there was no effect of animation for students' recall performance. Based on dual-coding theory, Mayer concludes in his studies that recall of verbal information relies heavily on encoding of verbal material, not visual material. Because both animation and static visual groups in this experiment were given the exact same verbal statements in same amount of time, it is assumed that they 
had equal opportunities to encode this verbal material into their long-term memory and, thus, both groups performed equally on the recall test. The findings from this study seem to confirm this claim. Therefore, this study concludes that there was no animation effect on recall of verbal information, because recall of verbal information mainly depends on encoding verbal material.

The second prediction, that field-independent students would perform better than field-dependent students, was confirmed for both measures of problem-solving and recall of scientific concepts. In fact, field-independent students generated approximately $35 \%$ more correct solutions to the problem-solving test and $20 \%$ more solutions to the recall test. Because of the ability of field-dependent students to effectively process and acquire visual information (Canelow, Taylor, \& Gates, 1980; Witkin, Goodenough, \& Oltman, 1979; Moore \& Dywer, 1991), it was expected that they would perform better than their field-dependent counterparts on acquisition of visual information. This prediction was confirmed on both problem-solving and recall tests, thus reinforcing the findings of earlier research that the cognitive style plays an important role on acquisition of visual information (Canelos, Taylor, \& Gates, 1980; Dwyer \& Moore, 1991; Dwyer \& Moore, 1992; Dwyer \& Moore, 1994; Moore, 1985; Moore \& Dwyer, 1991; Moore \& Dwyer, 1994). It appears that field-independent students were able to effectively focus on the essential cues and to easily restructure visual information, while field-dependents had difficulty identifying important cues 
and processing visual information. The findings provide a consistent picture of the role of individual differences in cognitive styles on learning from visualized instruction.

This study also predicted an interaction between presentation type (animation and static graphic) and students' cognitive style in learning from visualized instruction. The significant interaction between these two variables was not observed. However, two planned analyses, which were conducted to explore whether animation can compensate for the field-dependence-independence differences, revealed following important results.

When a comparison using a one-way ANOVA was conducted among students who received only the animated or static visual treatment, no differences in problemsolving performance were found between field-independents and field-dependents who received the animated visual treatment. Differences were found, however, in problemsolving performance between field-independents and field-dependents who received static visual instructional treatment, favoring field-independent students. The findings on students' problem-solving performance indicated the possibility of minimizing the differences between field-independents and field-dependents by using animated visual instructional material. In fact, animation enabled field-dependent students $(M=5.25)$ to perform at a similar level to that of field-independent learners $(M=6.24)$ as can be seen in Figure 5; while static visual failed to reduce achievement differences between field-independents $(M=5.64)$ and field-dependents $(M=3.78)$. It indicated that 


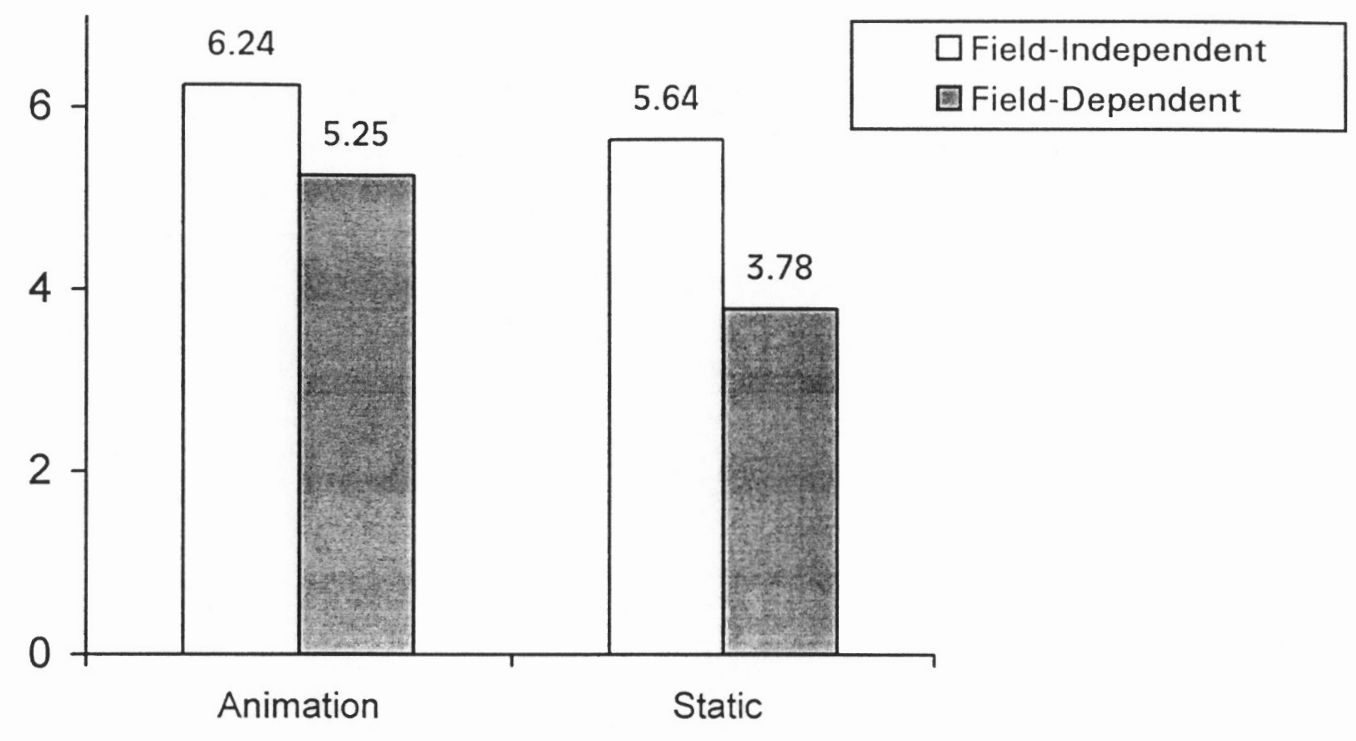

Figure 5. Mean Problem-Solving Scores for Field-Independents and FieldDependents in Each Animated and Static Visual Group

animation tended to be helpful for field-dependent learners in acquiring and processing knowledge from visual materials by effectively cueing their attention to the essential items of visual materials. The emphasis on essential parts of visuals using motion and trajectory might make the relevant cues more salient and obvious to field-dependent learners and aid those individuals in overcoming the influence of an irrelevant context. This result reveals that animation can provide clear benefits on problem-solving performance for field-dependent learners who have difficulty perceiving visual-spatial information.

However, when a similar comparison on the recall test was conducted among students who received only animated or static visual, significant differences were 
observed between field-independents and field-dependents on both animated $\left(M_{\mathrm{Fl}}=\right.$ $\left.8.40, M_{\mathrm{FD}}=7.63\right)$ and static visual groups $\left(M_{\mathrm{FI}}=8.41, M_{\mathrm{FD}}=6.28\right)$. That is, fielddependent students did not perform equivalently to field-independents on recall test. Again, this finding indicates that field dependents learners did not benefit from the animated visuals on recall of verbal information. Apparently, animation was not able to compensate for the differential achievement in the recall test occurring between field-dependents and field-independents. Because recall performance relies heavily on encoding of verbal material not visual material (Mayer, 1991; Mayer, 1992; Mayer, 1994), animation as a visual material did not affect students performance on recall in this experiment. Research (e.g., Carroll, 1993) suggests the possible reason for the differential performance occurring between field-independents and field-dependents in recall performance is that the degree of spatial ability affects the length of the memory spans. According to Carroll (1993, cited in Mayer \& Sims, 1994), the memory traces of field-dependents, who have low spatial ability, disappear faster than those of fieldindependents, who have high spatial ability.

The findings on the field-dependents' benefit from the use of an animated visual in problem-solving performance were also confirmed from the one-way ANOVA performed on the data obtained only from field-dependent participants. Field-dependent participants showed a significant difference between animation $(M=$ $5.25)$ and static $(M=3.78)$ visual groups on problem-solving performance; while they showed similar performance in both groups $\left(M_{\text {anim }}=7.63, M_{\text {static }}=6.28\right)$ on recall 
performance. The findings revealed the approximately $40 \%$ increase in the performance of field-dependent learners on the problem-solving test when they received the animation treatment instead the static visual treatment. It reveals that animation tended to make the learning task become more clear, structured, and easy for field-dependent learners to perceive the essential messages of the learning task. Again, the results confirmed the animation effect in compensating for the differential achievement between field-dependents and field-independents on problem-solving performance but not recall performance.

In general, this study indicates that animated visual has powerful influence on students' problem-solving transfer performance, especially for field-dependent learners who have difficulty acquiring visual information. Although the study has shown the significant impact of animation on students' learning, many questions were generated regarding the generalization of the findings. This investigation used the particular population and specific learning task. Thus, it is not appropriate at this stage to generalize too broadly from the findings. First, the generalization of the results must be limited to learning tasks similar to those which were chosen for this study. The study might have different results if other types of learning task (e.g., attitude and motor skill domains) are selected instead of the cognitive learning task used in this study. Secondly, the findings of this study must not be generalized to population other than ones picked in this study. In short, the results of this study must not be generalized to a much larger context, without replication with participants of different 
educational levels and with different types of learning tasks other than the learning of scientific concepts.

\section{Conclusion}

The results of this study indicate that an animated visual would be more effective in promoting problem-solving of scientific concepts than a static visual for the population used as participants -- undergraduate and graduate students who have low experience with mechanical items. Furthermore, the study supports the benefits of using computer animation for minimizing the differential achievement between fieldindependents and field-dependents on problem-solving performance. It indicates that animated visuals have the potential of making up for inherent differences between field-dependent and field-independents in performance on problem-solving task.

Multimedia is expensive to produce. The result of this study implies that it is worthwhile to spend time and effort producing animated instructional materials if the learning objective is to enhance the problem-solving performance of the scientific concepts. Simultaneously, this study alerts educators not to judge multimedia instructional materials by assigning too much weight on animated visuals if the learning outcome focuses solely on the retention of the presented material. Designing multimedia instructional material involves much more than incorporating new features or technological advances into the material. Better understanding of the unique 
attributes of animation and their relationship to learners' individual differences is one of the most important keys to successful and sound development of instructional material. Animation has the powerful potential to facilitate students' learning experiences, but to do so, educators must carefully examine the many factors influencing visual learning and use the features of animation more appropriately and carefully. In conclusion, the findings of this study not only contribute to growing literature on the cognitive psychology of visual instructional methods, but also indicate the potential of visually based instruction as a medium for compensating for the fieldindependent-dependent difference on problem-solving of scientific material.

\section{Recommendation for Future Research}

Based on the discussion stated earlier about the limitation of the study in the generalizability of the findings, this study is required to be replicated with participants of different educational levels and with different types of learning tasks other than the learning of scientific concepts. Additional research is also needed to investigate the animation effect on problem-solving when measured after a longer time lapse. Other research variables like animation complexity and color-animation linkages remain to be investigated. Another issue worthy of further study is the replication of this study considering the gender of participants as a possible source of interaction between the variable of animation. Also, it would be interesting to explore the relationship of 
animation to other types of individual differences of learners instead of the cognitive style chosen for this investigation. 


\section{REFERENCES}

Alessi, S. M. (1988). Fidelity in the design of instructional simulations. Journal of Computer-Based Instruction, 15, 40-47.

Baek, Y. K., \& Layne, B. H. (1988). Color, graphics, and animation in a computer-assisted learning tutorial lesson. Journal of Computer-Based Instruction, 15, $131-135$.

Bar-Haim, G., \& Wilkes, J. M (1989). A cognitive interpretation of the marginality and underrepresentation of women in science. Journal of Higher Education, 69, 371-387.

Canelos, J., \& Taylor, W. (1981). A networking information processing strategy and the learning of field dependents receiving visual instructional information. Journal of Experimental Education, 50, 42-46.

Canelos, J., Taylor, W., \& Dwyer, F. M. (1985). The effects of recall cue and cognitive trace compatibility when learning from visualized instruction: An application of encoding specificity. Instructional Journal of Instructional Media, 12, 167-178.

Canelos, J., Taylor, W., \& Gates, R. B. (1980). The effects of three levels of visual stimulus complexity on the information processing of field-dependents and field-independents when acquiring information for performance on three types of instructional objectives. Journal of Instructional Psychology, 7 (2), 65-70. 
Carroll, J. B. (1993). Human cognitive abilities: $\underline{\text { A Survey of Factor Analytic }}$ Studies. Cambridge, England: Cambridge University Press.

Champagne, A. B. \& Klopfer, L. E. (1984). Research in science education. Science Education, 171-189.

Clark, R. E. \& Salomon, G. (1986). Media in teaching, in : M. C. Wittrock (Ed.), Handbook of Research on Teaching (3rd ed., pp. 464-478). New York: MacMillan.

Craik, F. I. M., \& Lockhart, R. S. ( 1972). Levels of processing: a framework for memory research. Journal of Verbal Learning and Verbal Behavior, 11, 671-684.

Croft, R. S. (1995). The effect of attribute emphasis in photographic illustrations for concept attainment by learners having varying degrees of Field Dependence. Doctoral dissertation, Virginia Polytechnic Institute and State University, Blacksburg, VA.

Crosson, C. W. (1984). Age and field independence among women. Experimental Aging Research, 10, 165-170.

Dwyer, F. M. (1967). Adapting visual illustrations for effective learning. Harvard Educational Review, 37, 250-263.

Dwyer, F. M. (1978). Strategies for Improving Visual Learning, State College, Pennsylvania: Learning Services. 
Dwyer, F. M., \& Moore, D. M. (1991). Effect of color coding on visually oriented tests with students of different cognitive styles. The Journal of Psychology, $\underline{125}(6), 677-680$.

Dwyer, F. M., \& Moore, D. M. (1992). Effect of color coding on visually and verbally oriented tests with students of different field dependence levels. Journal of Educational Technology Systems, 20 (4), 311-320.

Dwyer, F. M., \& Moore, D. M. (1994). The effect of color coding and test type (visual/verbal) on students identified as possessing different field dependence levels.. British Journal of Educational Technology, 25 (3), 217-219.

Dwyer, F. M. (1972). A Guide for Improving Visualized Instruction. State College, Pennsylvania: Learning Services.

Dwyer, F. M. (1994). One dimension of visual research: A paradigm and its implementation. In D. M. Moore \& F. M. Dwyer (Eds.), Visual Literacy (pp. 381-402). Englewood Cliffs, New Nersey: Educational Technology Publications, Inc.

Educational Testing Service (1988). The Science Report Card : Trends an Achievement Based on the 1986 National Assessment. Princeton, NJ; Assessment of Education progress.

Fox, D., \& Waite, M. (1984). Computer Animation Primer. New York: McGraw-Hill Book Company.

Gibson, J. J. (1954). A theory of pictorial perception. AV Communications Review, 2, 3-23. 
Halpern, D. F. (1992). Sex Differences in Cognitive Abilities. Hillsdale, New Jersey: Lawrence Erlbaum Associates Publishers.

Hoftstein, A. \& Yager, R. E. (1982). Societal issues as organizers for science education in the '80s. School Science and Mathematics, 82 (7), 539-547.

Klein, D. (1987). Conditions Affecting the Effectiveness of Animated and Non-animated Displays in Computer-Based Instruction. Paper presented at the annual meeting of the Association for the Development of Computer-Based Instructional Systems, Oakland, CA.

Knowlton, J. Q. (1964). A Conceptual Scheme for the Audio-Visual Field, Bloomington: Indiana University, Bulletin of the School Board.

Kobayashi, S. (1986). Theoretical issues concerning superiority of pictures over words and sentences in memory. Perceptual and Motor Skills, 63, 783-792.

Large, A., Beheshti, J., Breuleux, A., \& Renaud, A. (1995). Multimedia and Comprehension: The relationship among text, animation, and captions. Journal of the American Society for Information Science, 46, 340-347.

Lawson, A. E., \& Wollman, W. T. (1976). Encouraging the transition from concrete to formal cognitive functioning: An experiment. Journal of Research in Science Teaching, 13 (5), 413-430.

May, M. A., \& Lumsdaine, A. A. (1958). Learning from Films, New Haven: Yale University Press. 
Mayer, R. E. (1989). Models for understanding. Review of Educational Research, 59, 43-64.

Mayer, R. E., \& Anderson, R. B. (1991). Animations need narrations: An experimental test of a dual-coding hypotheses. Journal of Educational Psychology, 83, 484-490.

Mayer, R. E., \& Anderson, R. B. (1992). The instructive animation: Helping students build connections between words and pictures in multimedia learning. Journal of Educational Psychology, 84, 444-452.

Mayer, R. E., \& Gallini, J. K. (1990). When is an illustration worth ten thousand words? Journal of Educational Psychology, 82, 715-726.

Mayer, R. E., \& Sims, V. K. (1994). For whom is a picture worth a thousand words? Journal of Educational Psychology, 86, 389-401.

McCloy. T. M., \& Koonce, J. M. (1982). Sex as a moderator variable in the selection and training of persons for a skilled task. Aviation, Space, and Environmental Medicine, 53, 1170-1172.

Merrill, P. F., \& Bunderson, C. V. (1981). Preliminary guidelines for employing graphics in instruction. Journal of Instructional Development, 4, 2-9.

Moore, D. M. (1985). Cognitive style, presentation mode in a visual location task. International Journal of Instructional Media, 12 (3), 179-184.

Moore, D. M., \& Dwyer, F. M. (1991). Effect of color coded information on students' levels of field dependence. Perceptual and Motor Skills, 72, 611-616. 
Moore, D. M., \& Dwyer, F. M. (1994). Effect of cognitive style on test type (visual or verbal) and color coding. Perceptual and Motor Skills, 79, 1532-1534.

Paivio, A. (1986). Mental Representations: A Dual Coding Approach. New York: Oxford University Press.

Pressley, M. (1977). Imagery and children's learning: Putting the picture in developmental perspective. Review of Educational Research, 47 (4), 585-622.

Purnell, K. N., \& Solman, R. T. (1991). The influence of technical illustrations on students' comprehension in geography. Reading Research Quarterly, 26, 277-296.

Reed, S. (1985). Effects of computer graphics on improving estimates to algebra word problems. Journal of Educational Psychology, 77 (3), 285-298.

Rieber, L. P. (1990). Animation in computer-based instruction. Educational Technology Research and Development, 38, 77-86.

Rieber, L. P. (1990a). Using computer animated graphics in science instruction with children. Journal of Educational Psychology, 77 (3), 285-298.

Rieber, L. P. (1994). Computers, Graphics, and Learning. Madison, Wisconsin: Brown \& Benchmark.

Rieber, L. P., Boyce, M. J. \& Assad, C. (1990). The effects of computer animation on adult learning and retrieval tasks. Journal of Computer-Based Instruction, 17, 46-52.

Rush, G. M., \& Moore, D. M. (1991). Effects of restructuring training and cognitive style. Educational Psychology, 11, 309-321. 
Sherman, J. A. (1967). Problems of sex differences in space perception and aspects of intellectual functioning. Psychological Review, 74, 290-299.

Williamson, V. M., \& Abraham, M. R. (1995). The effects of computer animation on the particulate mental models of college chemistry students. Journal of Research in Science Teaching, 32, 521-534.

Wise, R. E. (1984). The role of field independence in visual information processing. International Journal of Instructional Media, 11 (2), 133-140.

Witkin, H. A. (1950). Individual differences in ease of perception of embedded figures. Journal of Personality, 19, 1-15.

Witkin, H. A., Dyk, R. B., Faterson, H. F., Goodenough, D. R., \& Karp, S. A. (1962). Psychological Differentiation. New York: Wiley.

Witkin, H. A., \& Goodenough, D. R. (1981). Cognitive Styles: Essence and Origin. New York: International Universities Press.

Witkin, H. A., \& Goodenough, D. R., \& Oltman, P. K. (1979). Psychological differentiation: current status. Journal of Personality and Social Psychology, 37 (7), $1127-1145$.

Witkin, H. A., Lewis, H. B., Hertzman, M., Machover, K., Meissner, P., \& Wapner, S. (1972). Personality through Perception. New York: Wiley.

Witkin, H. A., Moore, C. A., Goodenough, D. R., \& Cox, P. W. (1977). Fielddependent and field-independent cognitive styles and their educational implications. Review of Educational Research, 47 (1), 1-64. 
Yager, R. E. (1989). New goals for students, Education and Urban Society, 22

(1), 9-22. 
APPENDIX A

ANOVA TABLES 
Summary of Two-Way ANOVA on Problem-Solving Test Scores

\begin{tabular}{c|c:c|c:c:c}
\hline Source & DF & Sum of Squares & Mean Square & F-Value & p-Level \\
\hline Cognitive Style & 2 & 41.414 & 20.707 & $7.135 \star$ & $0.001 \star$ \\
Presentation Type & 1 & 44.519 & 44.519 & $15.339 \star$ & $0.000^{\star}$ \\
Interaction & 2 & 6.374 & 3.187 & 1.098 & 0.337 \\
\hline
\end{tabular}

Summary of Two-Way ANOVA on Recall Test Scores

\begin{tabular}{c|c|c|c|c|c}
\hline Source & DF & Sum of Squares & Mean Square & $F$-Value & p-Level \\
\hline Cognitive Style & 2 & 51.762 & 25.881 & $8.427 \star$ & $0.00{ }^{\star}$ \\
Presentation Type & 1 & 9.389 & 9.389 & 3.057 & 0.083 \\
Interaction & 2 & 9.336 & 4.668 & 1.520 & 0.223 \\
\hline
\end{tabular}


Summary of One-Way ANOVA on Problem-Solving Test Scores

Animation

\begin{tabular}{c|c:c:c:c:c}
\hline Source & DF & Sum of Squares & Mean Square & F Value & p-Level \\
\hline Cognitive Style & 2 & 9.590 & 4.795 & 1.551 & 0.220 \\
\hline
\end{tabular}

$\underline{\text { Static Visual }}$

\begin{tabular}{c|c|c|c:c|c}
\hline Source & DF & Sum of Squares & Mean Square & F Value & p-Level \\
\hline Cognitive Style & 2 & 37.532 & 18.766 & $6.928 \star$ & $0.002 \star$ \\
\hline
\end{tabular}


Summary of One-Way ANOVA on Recall Test Scores

Animation

\begin{tabular}{c|c|c|c|c|c}
\hline Source & DF & Sum of Squares & Mean Square & F Value & p-Level \\
\hline Cognitive Style & 2 & 13.372 & 6.686 & $4.201 \star$ & $0.020^{\star}$ \\
\hline
\end{tabular}

Static Visual

\begin{tabular}{c|c:c|c:c:c}
\hline Source & DF & Sum of Squares & Mean Square & F Value & p-Level \\
\hline Cognitive Style & 2 & 47.670 & 23.835 & $5.207 \star$ & $0.008^{\star}$ \\
\hline
\end{tabular}




\section{Summary of One-Way ANOVA on Field-Dependents' Scores on the Problem-Solving and Recall Tests}

\section{Problem-Solving Test}

\begin{tabular}{c|c:c|c:c:c}
\hline Source & DF & Sum of Squares & Mean Square & F Value & p-Level \\
\hline Cognitive Style & 1 & 18.359 & 18.359 & $8.380 \star$ & $0.007 \star$ \\
\hline
\end{tabular}

Recall Test

\begin{tabular}{c|c:c|c:c:c}
\hline Source & DF & Sum of Squares & Mean Square & F Value & p-Level \\
\hline Cognitive Style & 1 & 15.374 & 15.374 & 3.384 & 0.075 \\
\hline
\end{tabular}


APPENDIX B

QUESTIONNAIRE 


\section{Questionnaire}

Last four digits of Student ID Number

Age

Put a check mark next to the things you have done

\begin{tabular}{|l|l|}
\hline Town a set of tools including screwdrivers, pliers, and wrenches. \\
\hline I own at least one power tools (such as a power saw or power drill). \\
\hline \begin{tabular}{l} 
I have replaced the heads on a lawn sprinkler system. \\
I have replaced the washer in a sink faucet. \\
\hline I have replaced the flush mechanism in a toilet. \\
\hline I have installed plumbing pipes or plumbing fixtures.
\end{tabular} \\
\hline
\end{tabular}

Put a check mark indicating your knowledge of how to fix household appliances and machines:

Very Much Much Average Little Very Little 


\section{APPENDIX C}

PROBLEM-SOLVING AND RECALL TESTS 


\section{Problem Solving Test}

Last four digits of Student ID Number

1. What could be done to make a pump more effective, that is, to move more air rapidly?

2. What could be done to make a pump more reliable, that is, to make sure it would not fail?

3. Suppose you push down and pull up the handle of a pump several times but no air comes out. What could have gone wrong?

4. Why does air enter a pump?

Why does air exit from a pump? 


\section{Recall Test}

Last four digits of Student ID Number

Please write down an explanation of how a bicycle tire pump works. Pretend that you are writing to someone who does not know much about pumps. 
APPENDIX D

EXAMPLE OF THE COMPUTER PROGRAM SCREEN 
You will receive a presentation about the operation of a bicycle pump.

\author{
Please notify the experimenter \\ when you are finished.
}

Click the mouse to begin 


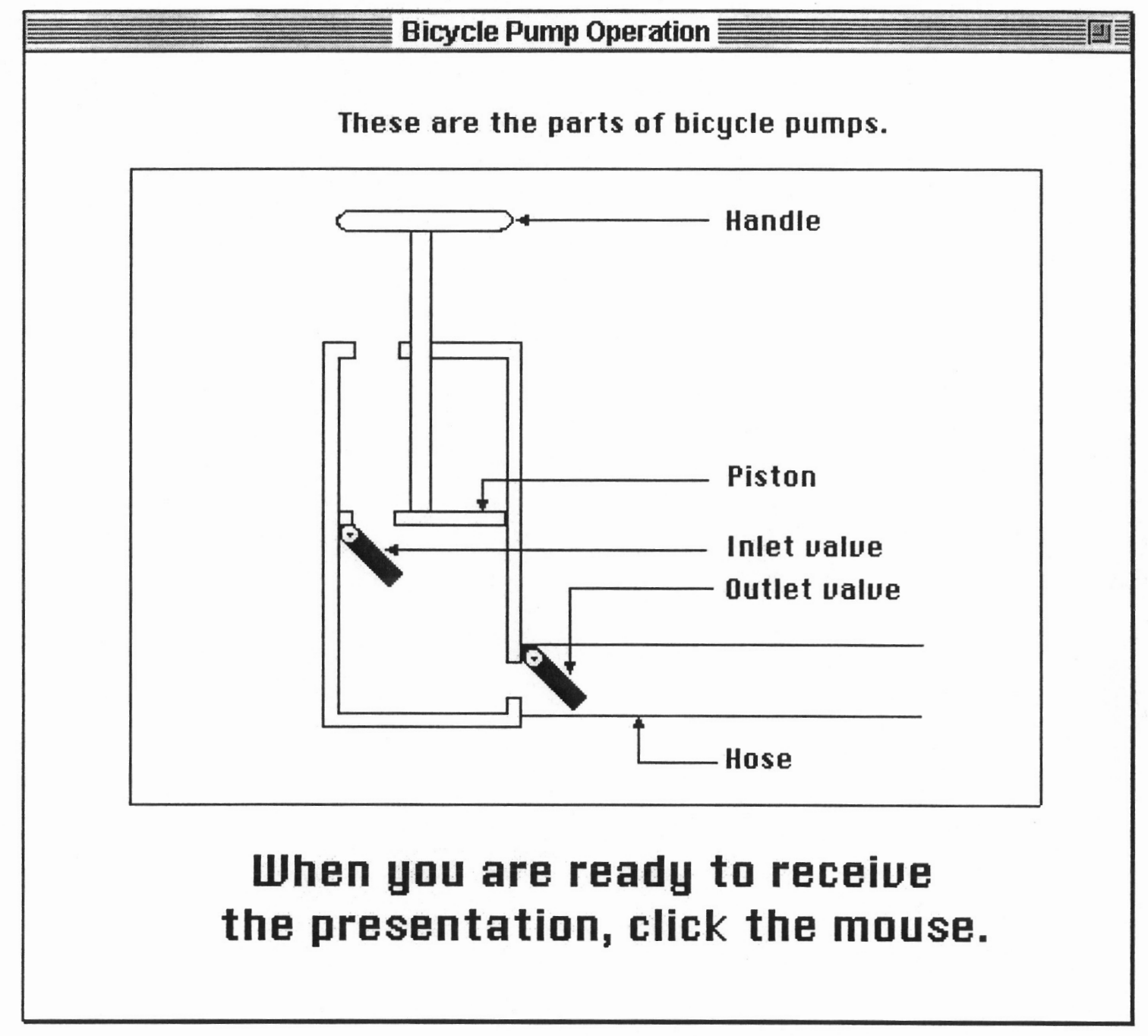




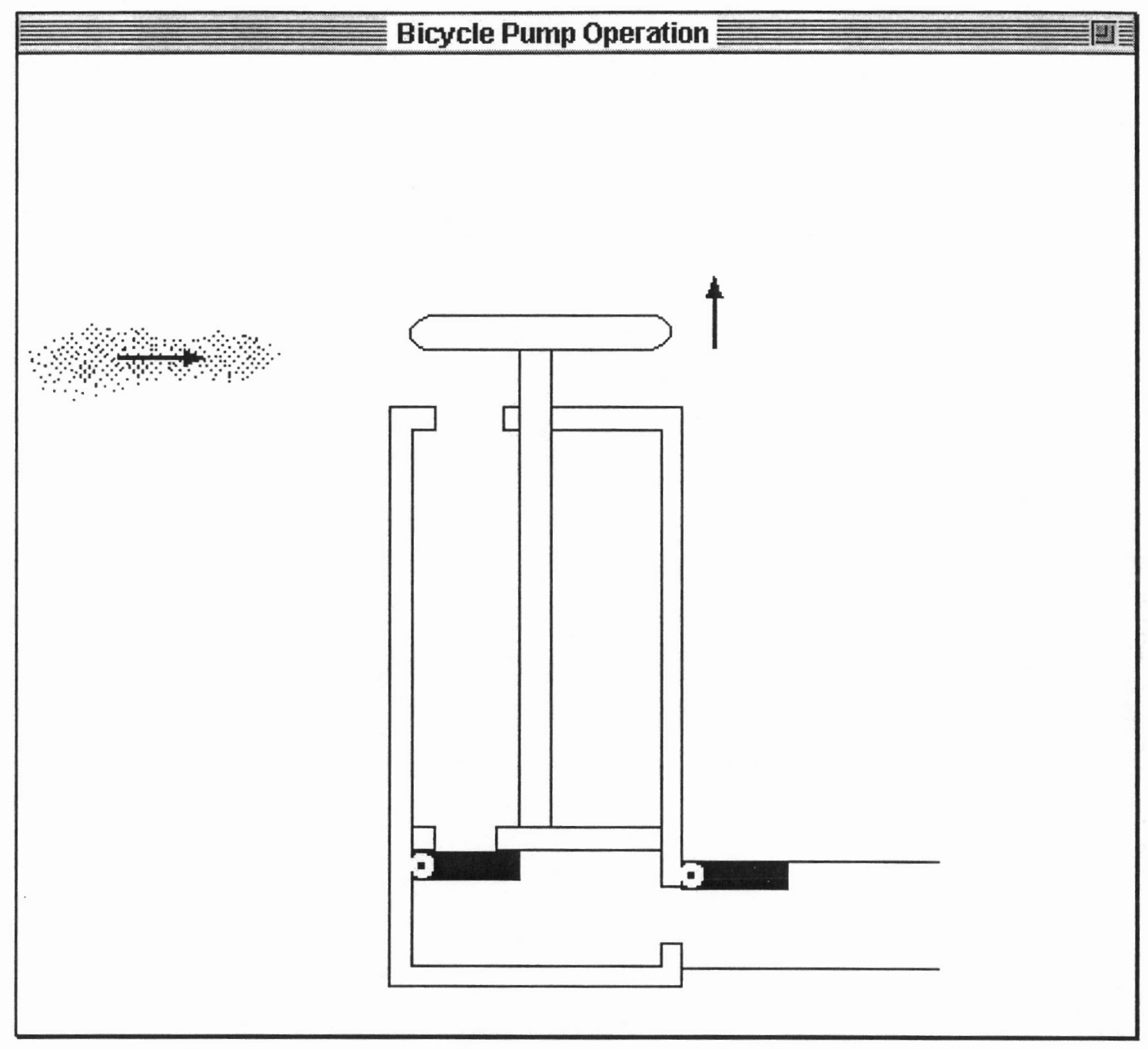




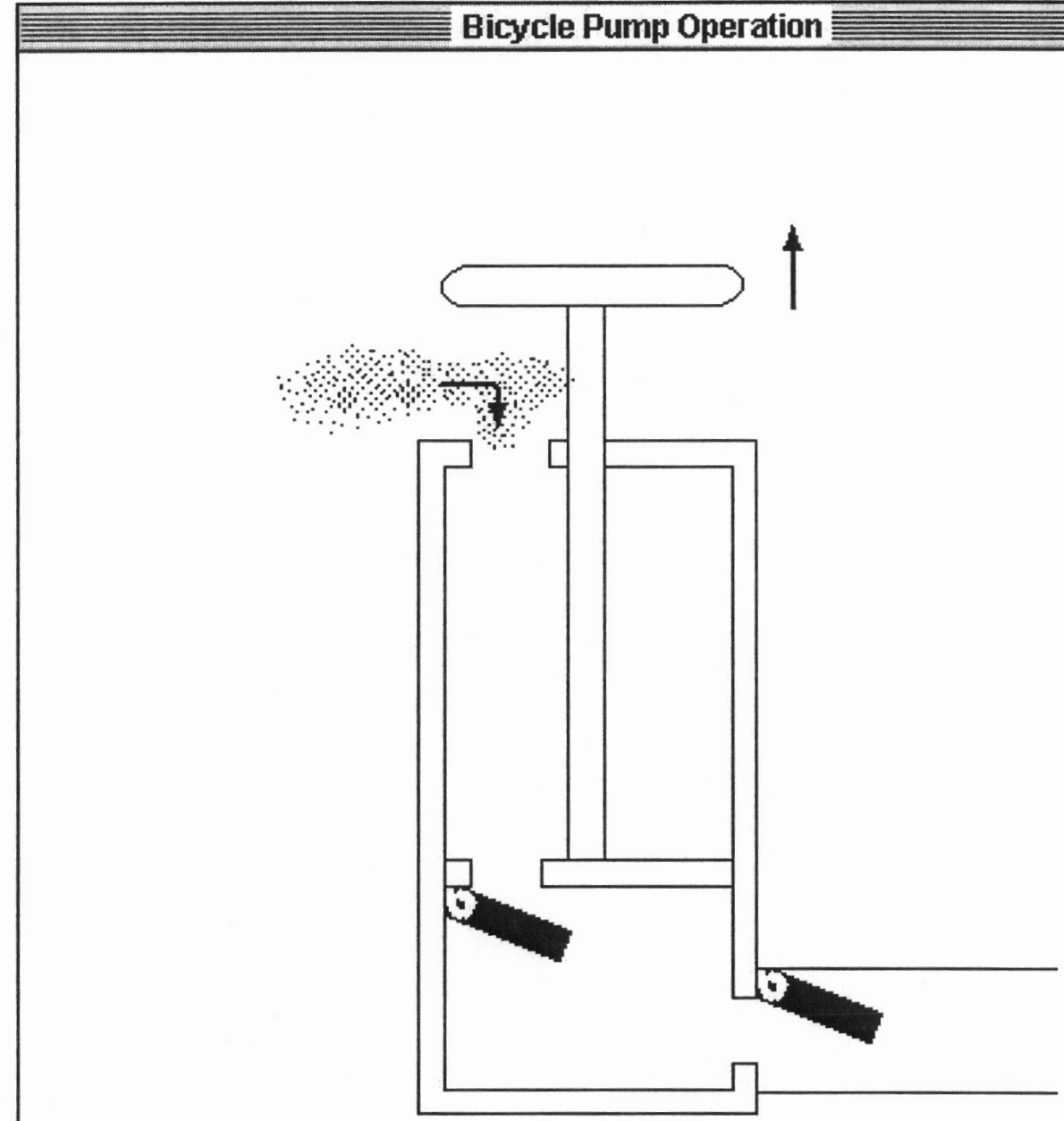




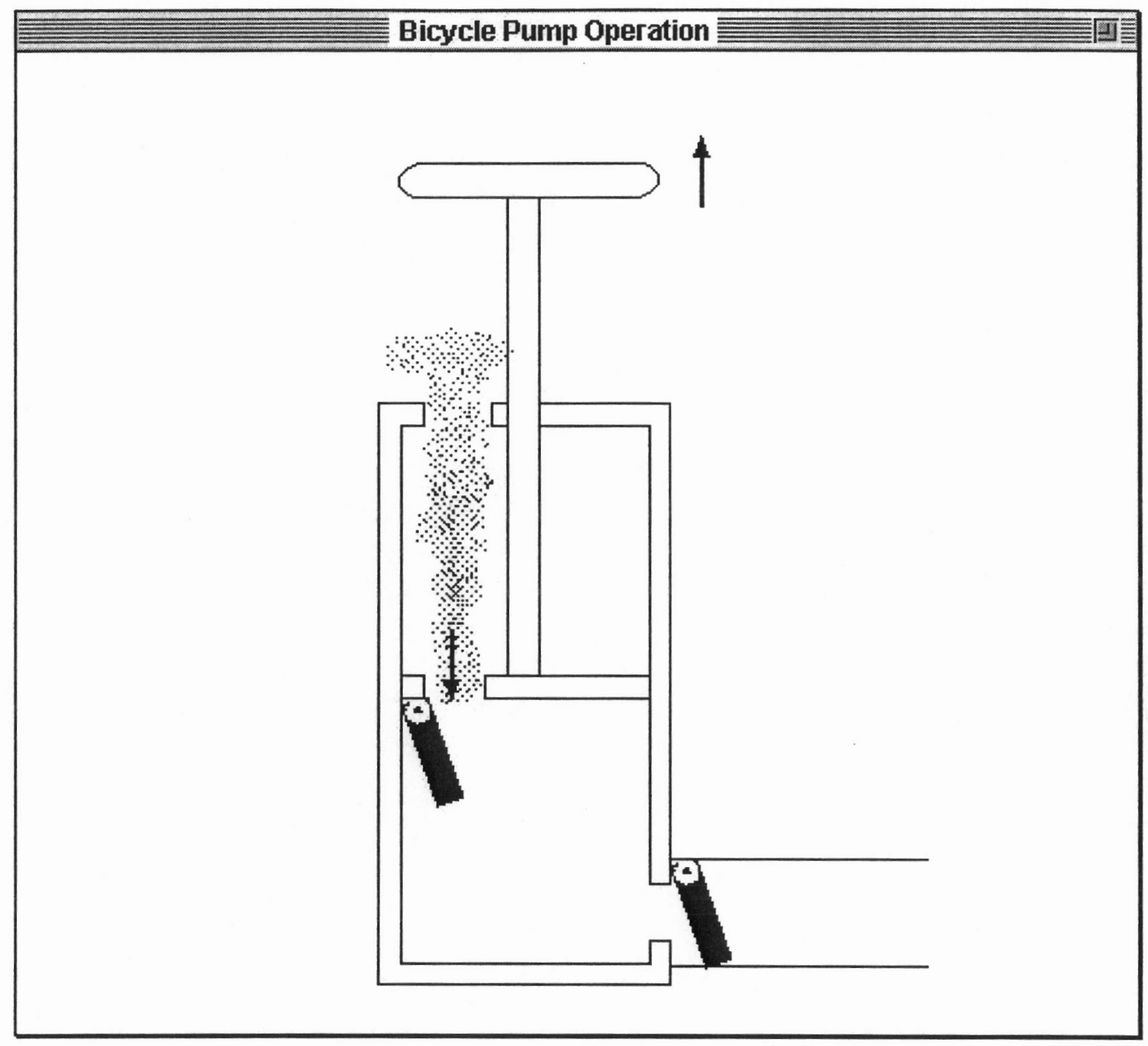









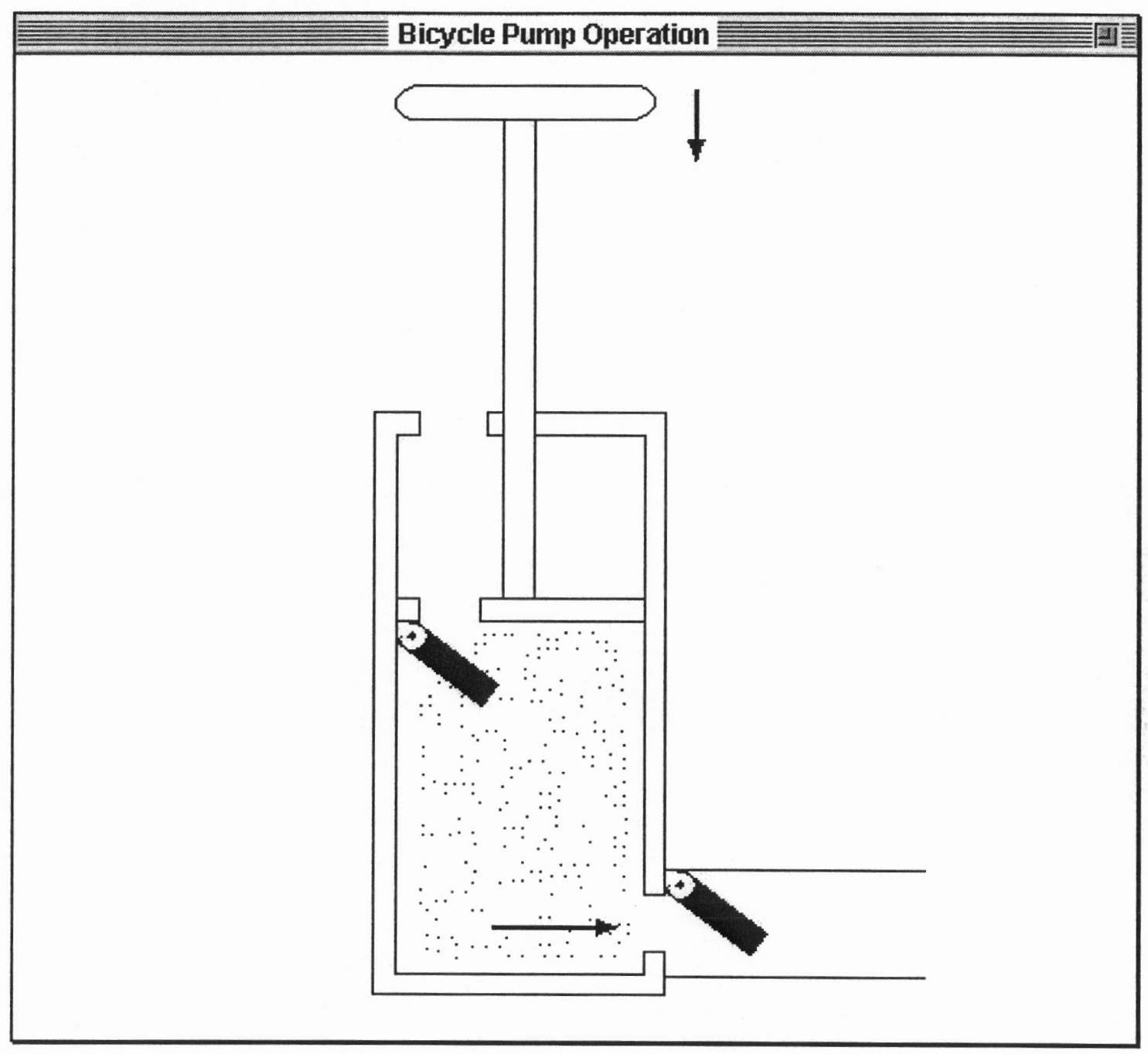




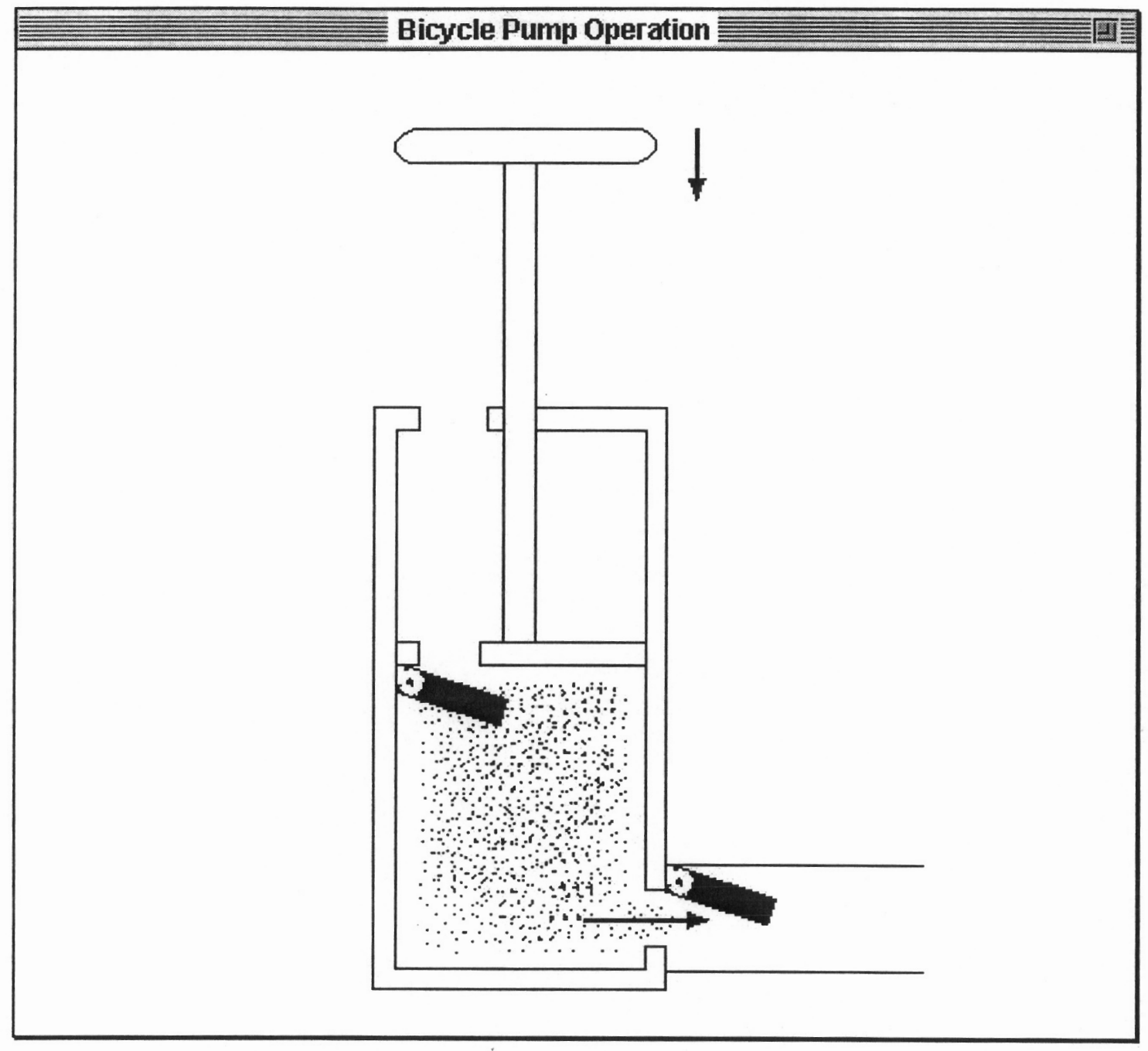




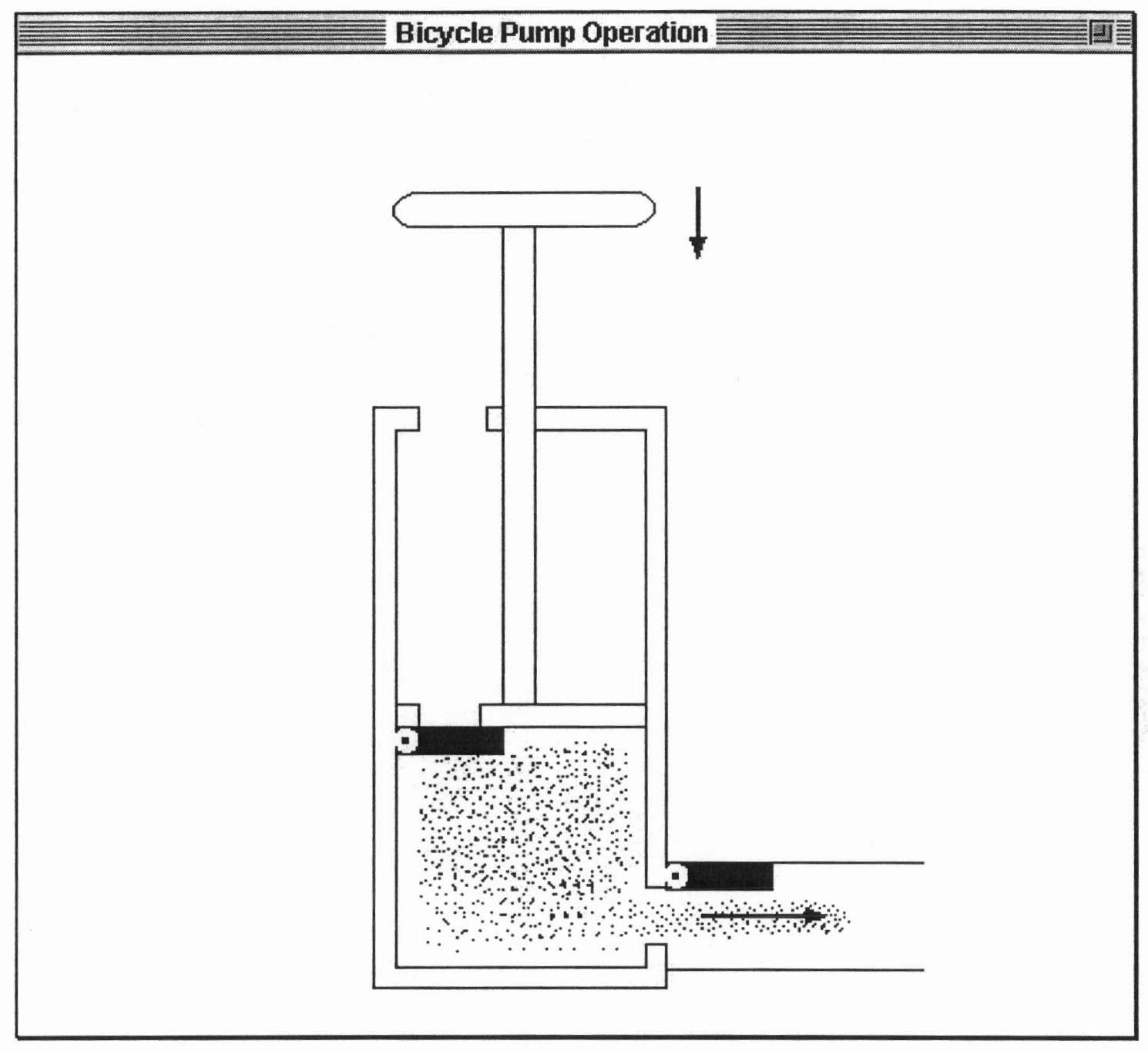




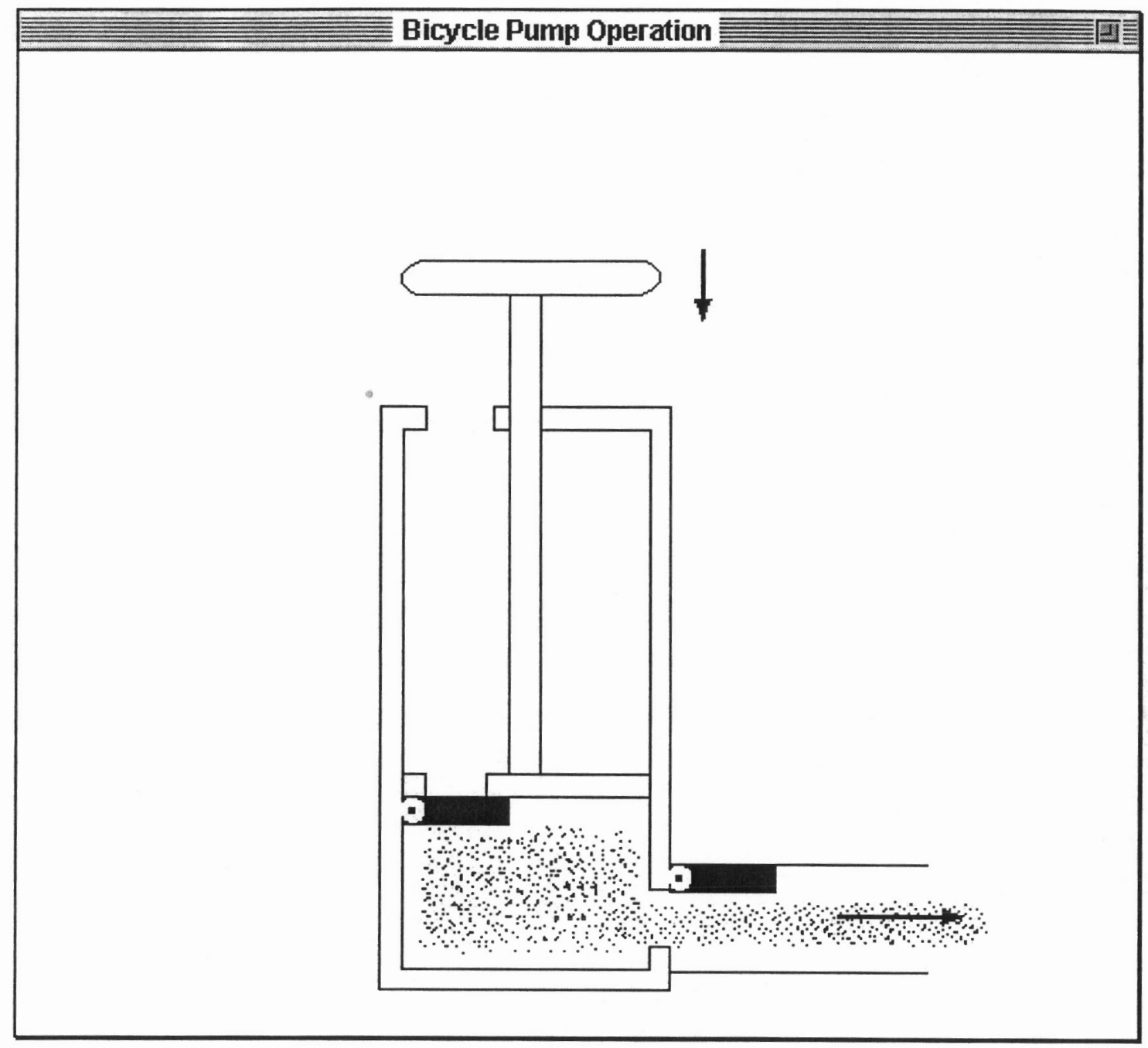







APPENDIX E

CONSENT FORM 


\section{VIRGINIA POLYTECHNIC INSTITUTE AND STATE UNIVERSITY}

\section{Informed Consent for Participants of Investigative Projects}

Title of Project: The Effects of Computer Animation and Cognitive Style on the Understanding and Retention of Scientific Explanation

Investigator: Sookyoung Lee

\section{I . The Purpose of this Research}

The purpose of this study is to investigate the attributes of animation and their relationships to the cognitive style with the goal of enhancing the understanding and retention of scientific concepts.

\section{Procedures}

The project involves:

1. Answering 8 questions about your experience about a bicycle pump mechanism.

2. Finding a simple geometric figure embedded within a more complex figure.

2. Watching and hearing a presentation of the bicycle pump mechanism.

3. Answering 6 questions about the bicycle pump mechanism

Viewing the presentation and completing the questions should take about 40 minutes. The research will be conducted at the room \# 220, War Memorial Hall.

\section{III . Risks}

There are no known risks to the participants of this research.

\section{Benefits of this Projects}

The research will help you understand how a bicycle pump operate. From this research, we hope to provide valuable information of how animation can compensate for the disadvantages of students who have difficulty perceiving visual information and how instructional designers can better develop computer animation which improve student learning. It is also hoped that the research will make a unique contribution to the theoretical and empirical rationale underlying the implementation of animation in the teaching and learning process.

\section{V . Extent of Anonymity and Confidentiality}

Please write down the last four digits of your student number on all answer sheets. This will be used only for data analysis of the research. All reports will be based on upon grouped data. No individual scores will be reported. 


\section{Freedom to Withdraw}

You are free to withdraw from this study at any time.

\section{VII . Approval of Research}

This research project has been approved, as required, by the Institutional

Review Board for Research Involving Human Subjects at Virginia Polytechnic Institute and State University, by the Department of Curriculum and Instruction.

\section{VIII . Subject's Responsibilities}

Participants have no specific responsibilities.

\section{IX . Subject's Permission}

I have read and understand the Informed Consent and conditions of this project. I have had all my questions answered. I hereby acknowledge the above and give my voluntary consent for participation in this project.

If I participate, I may withdraw at any time without penalty. I agree to abide by the rules of this project.

\section{Signature}

Date

Should I have any questions about the research or its conduct, I may contact:

Sookyoung Lee

Investigator

Dr. J. K. Burton

Faculty Advisor

E. R. Stout

Chair, IRB

Research Division

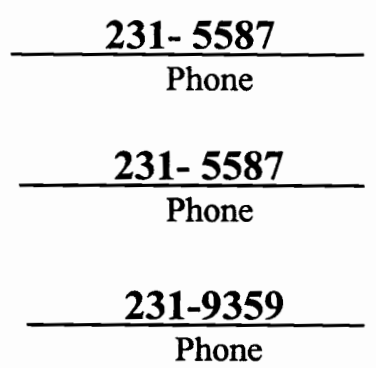

Phone 


\section{VITA}

\section{Sookyoung Lee}

EDUCATIONAL BACKGROUND

- Ph. D., Teaching and Learning / Instructional Systems Development Virginia Polytechnic Institute \& State University, Blacksburg, VA

December, 1996

- M. A., Curriculum and Instruction / Secondary School / Science

Virginia Polytechnic Institute \& State University, Blacksburg, VA December, 1994

- B. S., Biology ( Minor - Science Education ) Ewha Womans University, Seoul, Korea

December, 1991

ACADEMIC HONORS

- Phi Kappa Phi National Honor Society

- Tuition and Fee Scholarship, Virginia Polytechnic Institute \&

State University (1995-1996)

\section{EXPERIENCE}

- Graduate Assistant, Education Technology Lab, Virginia Polytechnic Institute \& State University. Blacksburg, VA (1996) Assisted College of Human Resources and Education faculty, staff, and students in computer hardware and software use and in basic skill training on computer and multimedia applications. 
- Graduate Research Assistant, Instructional Systems Development, Virginia Polytechnic Institute \& State University.

Blacksburg, VA (1995-1996)

Assisted in conducting the research of "scenario-based instructional design and evaluation of interfaces for the World Wide Web"

- Homepage Designer, College of Human Resources and Education, Virginia Polytechnic Institute \& State University.

Blacksburg, VA (1995-1996)

Developed the visual design of the homepage of the project "Healthy Heart" which is an funded interactive website for children in the intermediate grades to educate them about the heart.

Developed the visual design of the homepage of the "College of Human Resources and Education" (1996)

Developed the visual design of the homepage of the department of "Instructional Systems Development" (1995)

\section{PROFESSIONAL ACTIVITIES}

Burton, J. K., Erskine, Carter-Tod, D., \& Lee, S. Scenario based design and evaluation of interfaces for the World Wide Web. Paper presented at the conference of the International Visual Literacy Association, Cheyenne, WY. (1996)

Burton, J. K., Erskine, L., Carter-Tod, D., \& Lee, S. Scenario based evaluation of a College of Education WWW server interface. Paper presented at the conference of the Eastern Educational Research Association, Boston, MA. (1996)

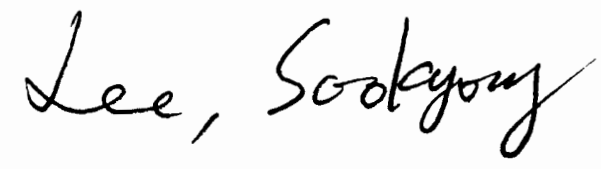

